\title{
Review of Power Converter Impact of Electromagnetic Energy Harvesting Circuits and Devices for Autonomous Sensor Applications
}

\author{
Mahidur R. Sarker ${ }^{1,2, *}$, Mohamad Hanif Md Saad ${ }^{1}$, José Luis Olazagoitia ${ }^{2} \mathbb{D}$ and Jordi Vinolas ${ }^{2} \mathbb{D}$ \\ 1 Institute of IR 4.0, Universiti Kebangsaan Malaysia (UKM), Bangi 43600, Selangor, Malaysia; \\ hanifsaad@ukm.edu.my \\ 2 Industrial Engineering and Automotive, Nebrija University, Campus de la Dehesa de la Villa, Calle Pirineos, \\ 55, 28040 Madrid, Spain; jolazago@nebrija.es (J.L.O.); jvinolas@nebrija.es (J.V.) \\ * Correspondence: mahidursarker@ukm.edu.my
}

Citation: Sarker, M.R.; Saad, M.H.M.; Olazagoitia, J.L.; Vinolas, J. Review of Power Converter Impact of Electromagnetic Energy Harvesting Circuits and Devices for Autonomous Sensor Applications. Electronics 2021, 10, 1108. https://doi.org/10.3390/ electronics 10091108

Academic Editor: Noel Rodriguez

Received: 21 March 2021

Accepted: 28 April 2021

Published: 8 May 2021

Publisher's Note: MDPI stays neutral with regard to jurisdictional claims in published maps and institutional affiliations.

Copyright: (c) 2021 by the authors. Licensee MDPI, Basel, Switzerland. This article is an open access article distributed under the terms and conditions of the Creative Commons Attribution (CC BY) license (https:// creativecommons.org/licenses/by/ $4.0 /)$.

\begin{abstract}
The demand for power is increasing due to the rapid growth of the population. Therefore, energy harvesting $(\mathrm{EH})$ from ambient sources has become popular. The reduction of power consumption in modern wireless systems provides a basis for the replacement of batteries with the electromagnetic energy harvesting (EMEH) approach. This study presents a general review of the EMEH techniques for autonomous sensor (ATS) applications. Electromagnetic devices show great potential when used to power such ATS technologies or convert mechanical energy to electrical energy. As its power source, this stage harvests ambient energy and features a self-starting and self-powered process without the use of batteries. Therefore, it consumes low power and is highly stable for harvesting energy from the environment with low ambient energy sources. The review highlights EMEH circuits, low power EMEH devices, power electronic converters, and controllers utilized in numerous applications, and described their impacts on energy conservation, benefits, and limitation. This study ultimately aims to suggest a smart, low-voltage electronic circuit for a low-power sensor that harvests electromagnetic energy. This review also focuses on various issues and suggestions of future EMEH for low power autonomous sensors.
\end{abstract}

Keywords: electromagnetic device; energy harvesting; autonomous sensors; low power

\section{Introduction}

The harvesting of electromagnetic energy from ambient environments has attracted much interest recently. Micro energy harvesters are small, vibration-driven electromagnetic transducers that harvest ambient energy for conversion into electrical charge. The features of sample electromagnetic energy harvesting (EMEH) are investigated in [1-3], and the achievement levels of some energy harvesting (EH) techniques are explained in Table 1 [4]. These techniques can usually produce charge for low power wireless sensor networks (WSNs) applications $[5,6]$. As an aim to facilitate the natural and causal interaction between such devices and humans, the embedding of ubiquitous computation into environments has drawn significant research attention along with the concepts of sensation and perception. Examples of such systems are WSNs, which show potential applicability in many areas [7-9]: piezoelectric conversion technology [10-12], solar system [13], thermoelectricpowered [14], and wind power systems $[15,16]$. These systems are capable of harvesting energy from ambient environments, which activate devices directly and finally store harvested energy in infinite capacity batteries for future use [17]. Conventional, chemical batteries provide the required power to each sensor node. However, they are large, expensive, and often tough to change frequently. Thus, the development of such systems is greatly limited. Various energy sources are used to power micro-level unmanned systems. 
Table 1. Energy harvesting approach and their verified capabilities.

\begin{tabular}{cc}
\hline Harvesting Method & Performance \\
\hline Radio frequency & $10 \mu \mathrm{W}$ \\
Wind & $20 \mathrm{~mW}$ \\
Temperature $\left(\Delta T=5^{\circ} \mathrm{C}\right)$ & $60 \mu \mathrm{W}$ \\
Mechanical vibration & $3.35 \mathrm{~mW}$ \\
Automotive light sensor & $1.03 \mathrm{~mW}$ \\
\hline
\end{tabular}

Figure 1 shows a block diagram of a dual-source EH system [18,19]. In the dualenergy source energy harvesting system, two energy harvesters get ambient energy from the surroundings, after processing provides the output to the load. Because there are dual-energy sources, there are two levels of output voltages. Conventional electromagnetic batteries are normally utilized to power WSNs, which have gained significant attention because of their applicability in monitoring plans, resources, and infrastructures [20,21]. Although the power requirements of electronic devices decrease as they become energy efficient, batteries are still their main power source. Batteries need to be recharged or replaced, and the proper disposal and recycling of batteries is a global challenge [22,23]. They are also heavy, especially when compared with microelectronic devices to which they supply power. A typical battery has a short life span and is thus not practical for devices, which are expected to last more than 10 years [24,25]. In addition, some electronic devices are located in hard-to-reach areas: embedded in people or animals, installed inside structures (bridges, roads, and buildings), placed in satellite systems, etc. EH is a potential solution that can provide power to these applications.

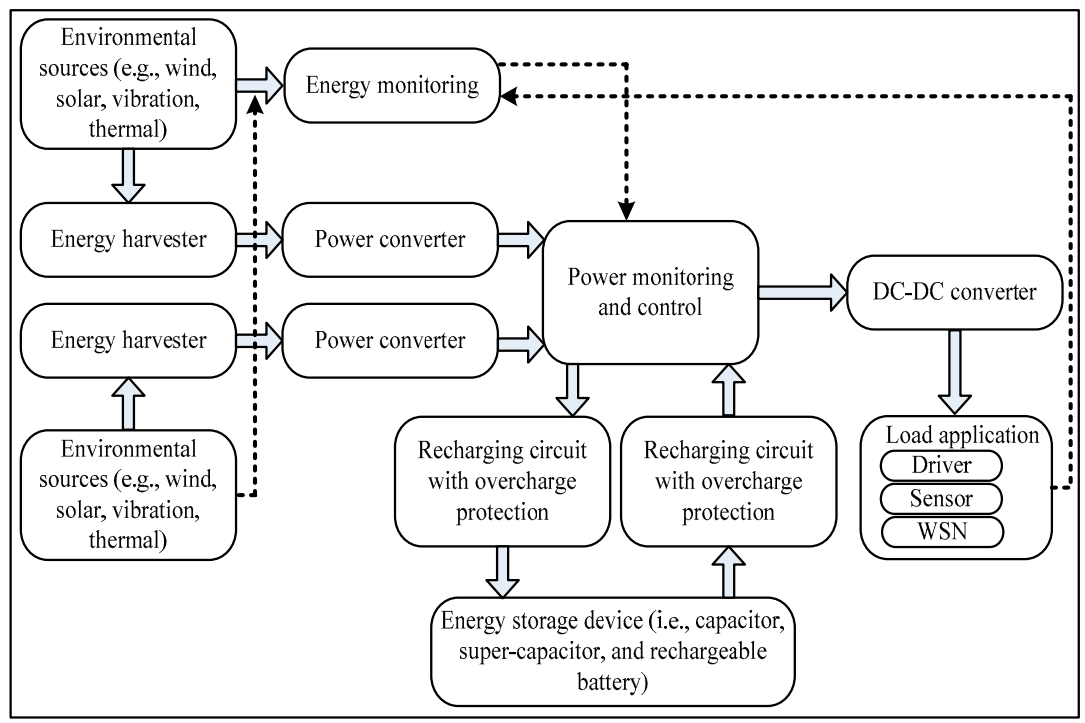

Figure 1. Block diagram of a dual-source energy harvesting system.

A single EMEH transducer can obtain energy from multiple natural sources. The harvesting electrical charge needs to monitor, control, and storage to utilize it in the load. Thus, a constant energy source is necessary for some WSNs applications. In 2011, around 150-200 million WSNs were utilized in the remote industrial areas to monitor and control the health of the equipment, safety, bio-medical application, defence application, and intelligent gathering [26,27]. Thus, the present study ultimately aims to suggest low-power EMEH devices with low power electronic circuit, which can be integrated into WSNs nodes for ATS $[28,29]$. The overall architecture of a typical block diagram of EMEH is shown in Figure 2; it contains three core components: EMEH sources, energy conversion devices/power electronic converters, and energy storage with the load. 


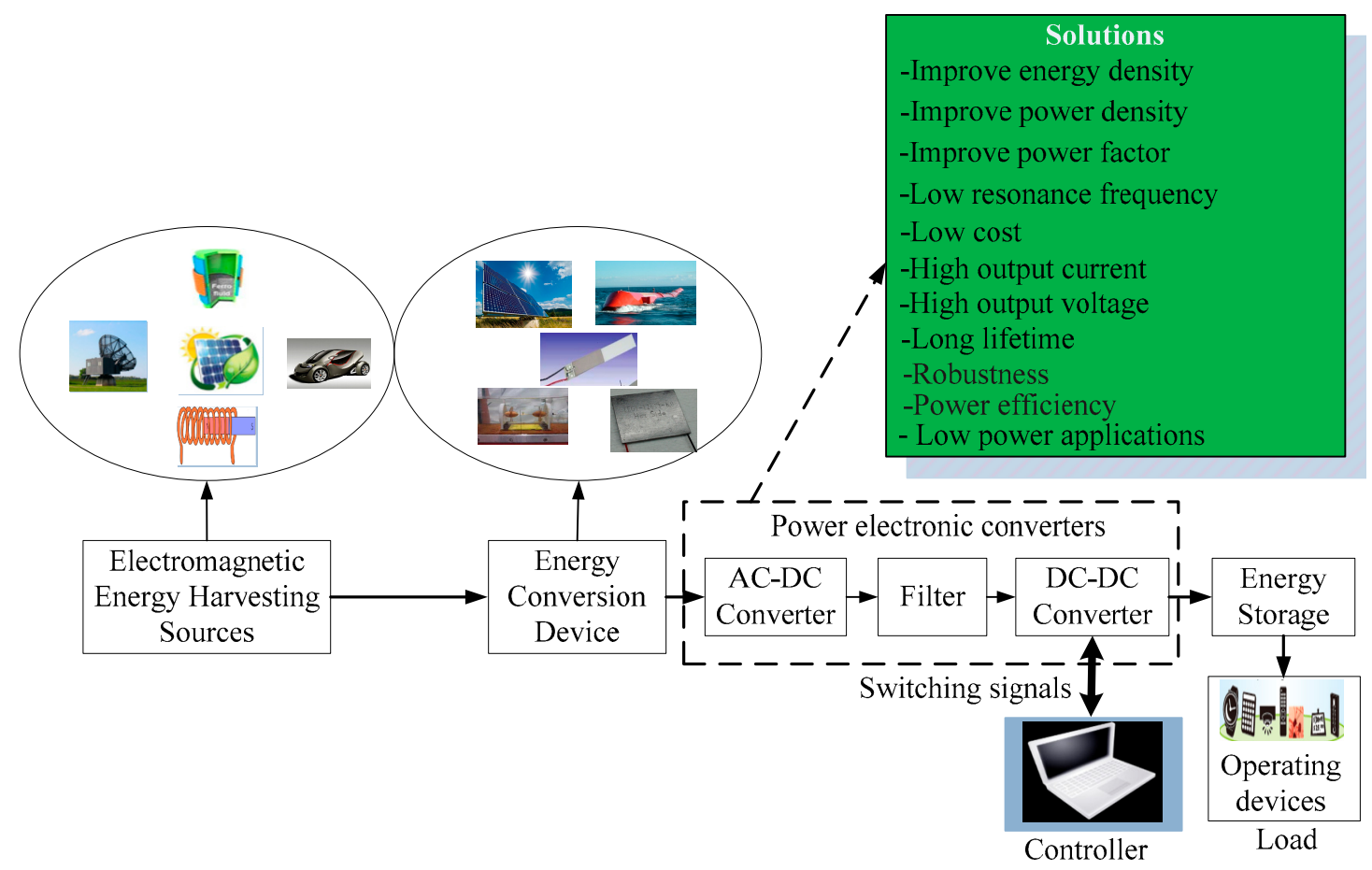

Figure 2. The typical block diagram of EMEH system.

The rest of this paper is organized as follows: Section 2 describes the phenomenon of electromagnetic system. Section 3 describes the relation between electromagnetic energy harvesting and autonomous sensors. Section 4 describes detailed power electromagnetic technologies for electromagnetic energy harvesting systems. Section 5 presents an overview of electromagnetic energy harvesting techniques and prototypes. Section 6 highlights the issues and challenges and, finally, conclusions and recommendations are presented in Section 7.

\section{Phenomenon of Electromagnetic}

The fundamental characteristics of electromagnetic devices are the generation of energy through electromotive force as shown in Figure 3 [30-32]. The electromagnetic system is based on Faraday's law of electromagnetic induction. The conduct of Faraday's law is associated with the voltage or electromotive force (emf) that induces magnetic flux linkage in a circuit, according to the following equation: [31].

$$
V=-\frac{d \phi}{d t}
$$

where $V$ is induced emf, $\phi$ is flux linkage, and $t$ is time. Usually, the circuit consists of various tune wires of coil during implementation to a generator, shown by:

$$
V=-\frac{d \Phi}{d t}=-N \frac{d \phi}{d t}
$$

where $\Phi$ is total flux linkage and $N$ is turns of coil. Basically, the total flux linkage for a various turn coil is estimated by:

$$
\begin{gathered}
\Phi=\sum_{i=1}^{N} \int_{A_{i}} B \cdot d A \\
V=-N A \frac{d B}{d t} \sin (\alpha)
\end{gathered}
$$


where $B$ is density of the magnetic flux at each coil segment, $i$ is the current of the coil tune, and $\Phi=N B A \sin (\alpha)$ where $\alpha$ is the angle between the coil area. Equation (4) can be expressed by:

$$
V=-\frac{d \Phi}{d x} \frac{d x}{d t}=-N \frac{d \Phi}{d x} \frac{d x}{d t}
$$

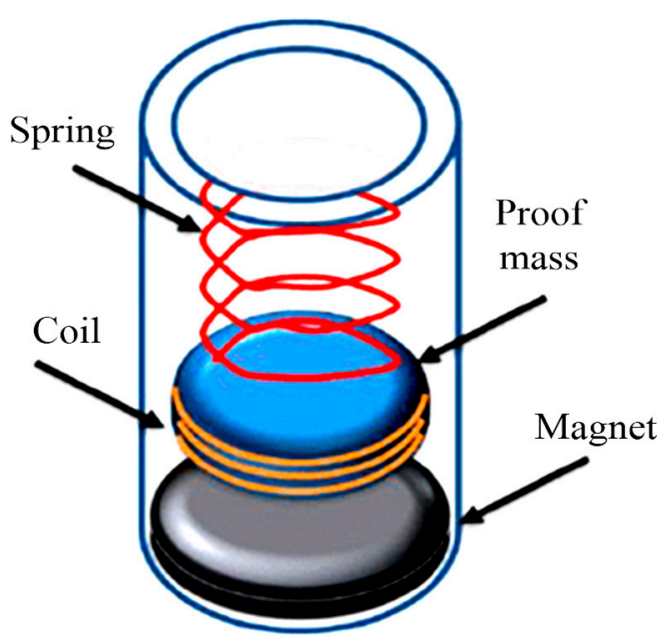

Figure 3. Feature of the electromagnetic energy harvester [30]. (Reprinted from ref. [30]).

The magnetic force on the magnet is given by:

$$
F_{m a g}=D_{m a g} \frac{d x}{d t}, F_{m a g}=\frac{d x}{d t}=\frac{V^{2}}{R_{L}+R_{C}+j \omega L_{C}}
$$

where $F_{m a g}$ is generator indication, $R_{L}$ is the load resistances, $R_{C}$ is the coil resistances, $j$ is the complex number and time variable, and $L_{C}$ is the coil inductance. The following equation can be expressed utilizing Equation (5):

$$
D_{m a g}=\frac{1}{R_{L}+R_{C}+j \omega L_{C}}\left(\frac{d \Phi}{d x}\right)
$$

where $D_{\text {mag }}$ is the electromagnetic damping. The following equation can express the maximum power extracted with the electromagnetic force:

$$
P_{\max }=F_{\operatorname{mag}} \frac{(t) d x(t)}{d t}
$$

The performance of the EMEH generator is depending on the combination of the material. Therefore, the material selection plays an important role to boost up the efficiency of power in the EMEH system. The category of magnet and which types of material used in the magnet define the magnetic field power.

\subsection{Mounting of Electromagnetic Vibration Generators}

The electromagnetic vibration generators (EMVG) produce power from the ambient sources through mechanical vibrational force, where structure acts as a magnetic circuit $[33,34]$. To extract electrical charge from the EMVG, this depends on the number of coil turns, damping, flux connection slope, and load impedance [35-37]. However, as compared to conventional electromagnetic generators, the micro-electromagnetic power generator produces high power. The study in $[33,38]$ developed an electromagnetic generator using a circular stable magnet tuning. The work in [39] proposed a piezoelectric bimorph cantilever beam for harvesting energy, utilizing magnetic attraction. In [40], the authors described a magneto-electric harvester based on a stable magnet and a piezoelec- 
tric harvester utilizing a metal ball. The structure of the electromagnetic power generator and $\mathrm{EH}$ based on vibration is shown in Figure 4a,b [41,42]. This feature includes a coil sandwiched between magnets, where two sets, oppositely separated, comprise the higher and lower magnets. This reverse split generates a flux slope in the direction of motion for the coil, which is in the x-direction in this case. Figure 4a shows a flux generator axial rotor, normally attached to the tube and covered by a ball bearing that retains the small gap between the magnets and the copper windings to increase the output power. The basic structure of the linear vibration-based $\mathrm{EH}$, which maintains a small gap between the winding and magnet array, is shown in Figure $4 \mathrm{~b}$. The power and dimension of a mass that produces $\mathrm{NdFeB}$ magnetic material with a vibration rate of $100 \mathrm{~Hz}$ and a vibration acceleration level of $1 \mathrm{~m} / \mathrm{s}^{2}$ is shown in Figure 5 . The graph shows a power density of almost $2.3 \mu \mathrm{W} / \mathrm{mm}^{3}\left(2.3 \mathrm{~mW} / \mathrm{cm}^{3}\right)$ for a system with a size of $1 \mathrm{~cm}^{3}$. In Figure 5, the graph is representing the power on the y-axis and the dimension of the electromagnetic vibrational generator on the $\mathrm{x}$-axis.

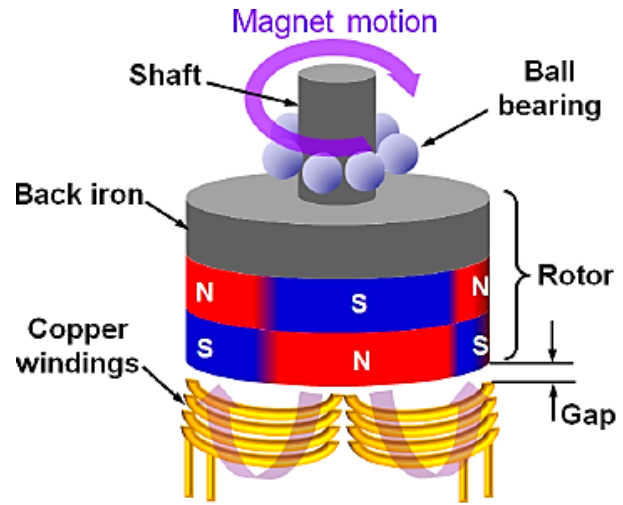

(a)

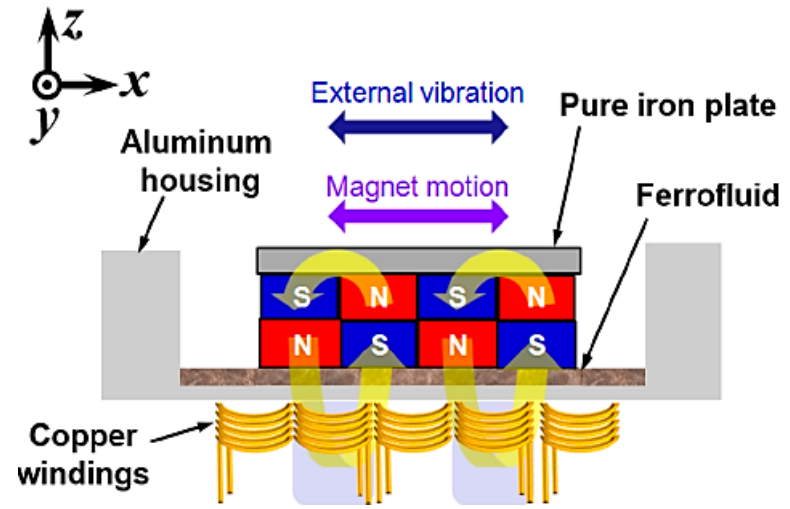

(b)

Figure 4. Structure electromagnetic vibration generator: (a) flux generator, (b) structure of the linear vibration-based energy harvesting [41,42].

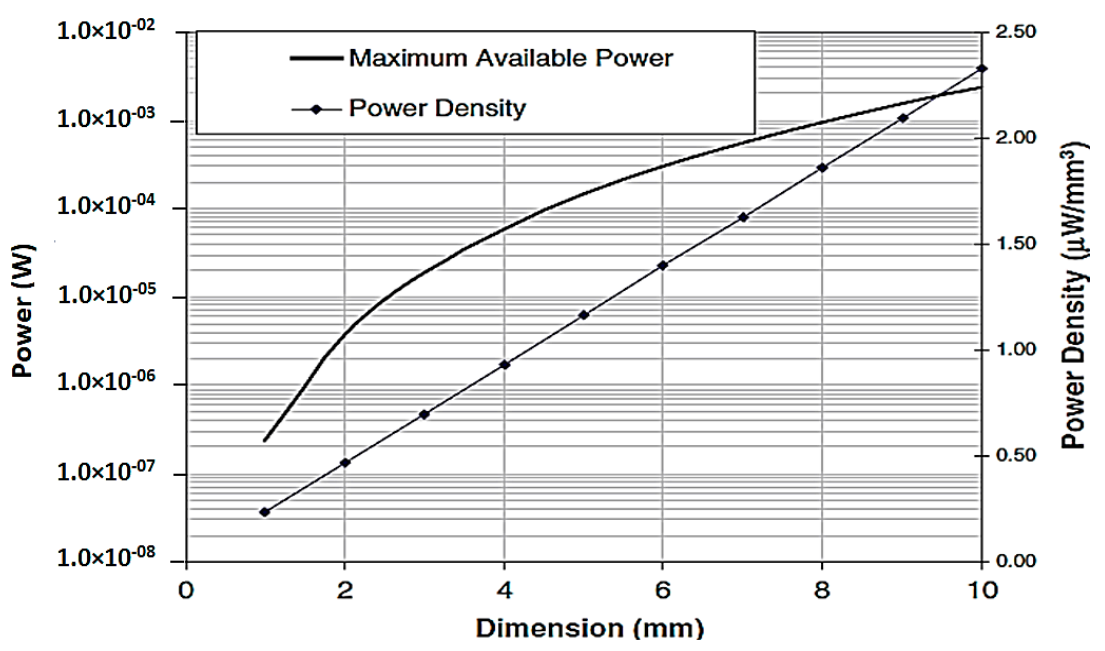

Figure 5. Power density with maximum available power dimension for the electromagnetic vibration generator structure [42].

The following equation indicates that the average power generated via the mass damping force is:

$$
P_{D}=\frac{1}{T} \int_{0}^{T} F_{D} \cdot U d t=\frac{(m a)^{2}}{2 D}
$$




$$
x_{m}=\frac{m a}{D \omega}
$$

Therefore, the average power can be expressed as:

$$
P_{D}=\frac{m \cdot a \cdot x_{m} \omega}{2}=\frac{\rho \cdot x_{m a s s} y \cdot z \cdot\left(x-x_{m a s s}\right) \omega}{4}
$$

here, $D$ is the displacement; $a$ is the acceleration; $m$ is the mass; $F$ is the force; $\rho$ is the density of the material; $x_{m}$ is the peak displacement of mass; and $x_{\text {mass }}, y$, and $z$ are the dimensions of the mass of materials. From Equation (11), after differentiating with respect to $x_{m}$, the following equation is obtained for the optimum length of mass for maximum power:

$$
x_{\text {optmass }}=\frac{x}{2}
$$

\subsection{Mounting of Electromagnetic Damping}

The electromotive force is induced by motion relative to the magnetic field, which causes an eddy current [43]. Eddy currents arise when a magnetic field shifts inside a conductor that causes electrical current loops in the conductor. Eddy currents can strain the motion that is involved, a fact that is known as magnetic damping [44,45]. Figure 6 shows the schematic diagram of electromagnetic damping [46].

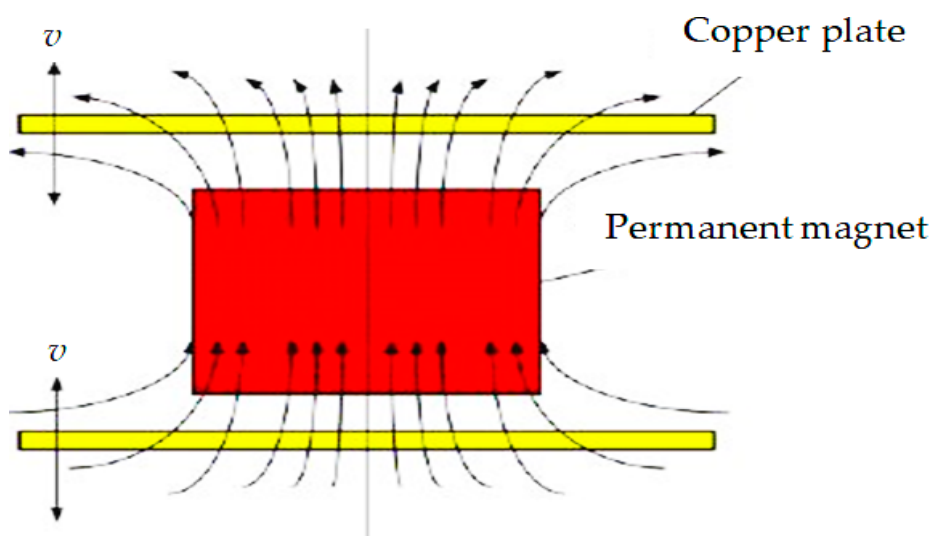

Figure 6. Schematic diagram of electromagnetic damping [46]. (Reprinted from ref. [46].

The following equation can express the magnitude of magnetic damping $[47,48]$ :

$$
\xi_{e}=\frac{\left(N B L_{c} C^{2}\right)}{2 m_{e} \omega_{1}\left(R_{c}+R_{L}\right)}
$$

where $m_{e}$ is the mass of electromagnetic resonator, $N$ is the number of turns of the coil, $B$ is the strength of the magnetic field, $L_{c}$ is the effective length of the coil, $C$ is the coil fill factor and the value of $C$ should be high, $R_{c}$ is the coil resistance, and $R_{L}$ is the load resistance. Usually, there are three kinds of electromagnetic damping as shown in Equation (14):

$$
\zeta_{l}=\zeta_{m}+\zeta_{h}+\zeta_{a}
$$

where $\zeta_{m}$ is the materials damping, $\zeta_{h}$ is the thermoelastic damping, and $\zeta_{a}$ is the air damping. Figure 7 shows effective power variation, which can be generated through numerous coil technologies [48]. The graph is representing the power on the $y$-axis and the dimension of the wire coil and planar micro coil of the generator on the x-axis. 


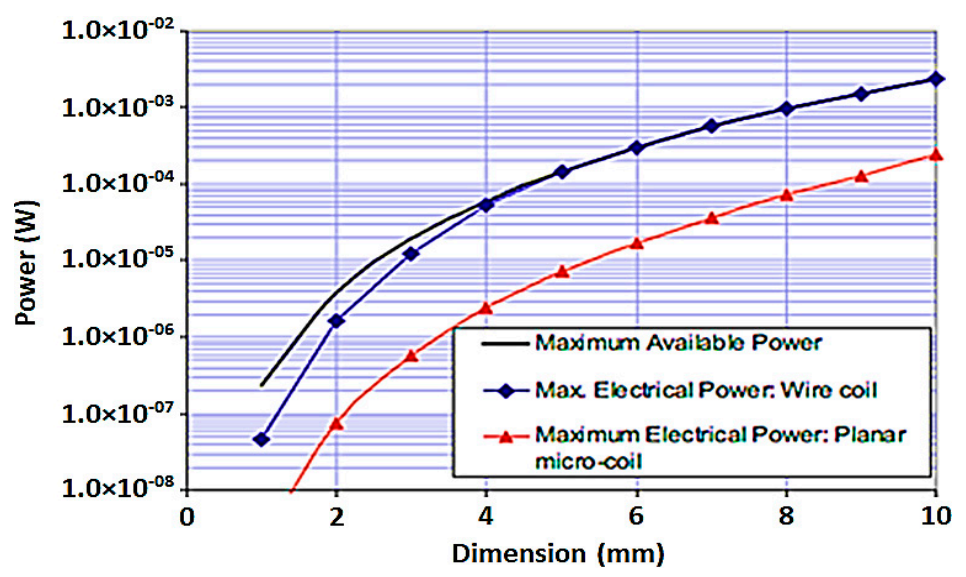

Figure 7. Highest possible electrical power generated from the wire coil and a micro-fabricated coil.

\subsection{Maximum Power from an Electromagnetic Generator}

The maximum power generation depends on the maximum displacement of the mass of the electromagnetic (EM) generator. The maximum electrical power, the resonance of the EM generator, is shown by Equation (15) [40,49]:

$$
P_{\max }=\frac{(m a)^{2}}{8 D_{P}}
$$

where $P_{\max }$ is the maximum electrical power, $D_{P}$ is the parasitic mechanical damping, $m$ is the mass, and $a$ is the acceleration. The following Equation (16) denotes EM damping to parasitic damping with readjusting the load to get the optimum resistance of the load, which produced maximum power:

$$
R_{I}=\frac{N^{2}\left(\frac{d \phi}{d x}\right)^{2}}{P_{D}}-R_{C}
$$

However, in the real condition based on the availability to produce power, the load is fixed. The following Equation (17) shows the optimum load resistance that increases the highest power:

$$
R_{I}=R_{C}+\frac{N^{2}\left(\frac{d \phi}{d x}\right)^{2}}{P_{D}}
$$

\section{Relation between Electromagnetic Energy Harvesting and Autonomous Sensors}

Usually, in wireless sensor networks, ATS is utilized for conducting real-time data and active low power devices. In the real-time data, the ATS senses any variation in the parameters and transmits that variation in the form of a voltage signal at the same time. On the other hand, active low power devices are basically logic gates acting like a switch and attached with sensors [50,51]. WSNs have different applications such as bio-medical [52,53], Internet of Things (IoT) [54], and environmental monitoring [55]. An ATS can run automatically with low power mode when it is required to sense the change in any parameter, processing the change in the form of the voltage signal, and transmitting that signal [56]. Figure 8 shows the general architecture of the ATS, in which the power source is delivering energy based on the demand of the load. The purpose of the power conditioning circuit is to provide a stabilized voltage, and an enhanced and filtered output to the load $[57,58]$. The system for storing purposes can use a battery or capacitor. However, the battery has a limitation in terms of recharging required after a certain period. Therefore, an EMEH system can be an alternative solution. 


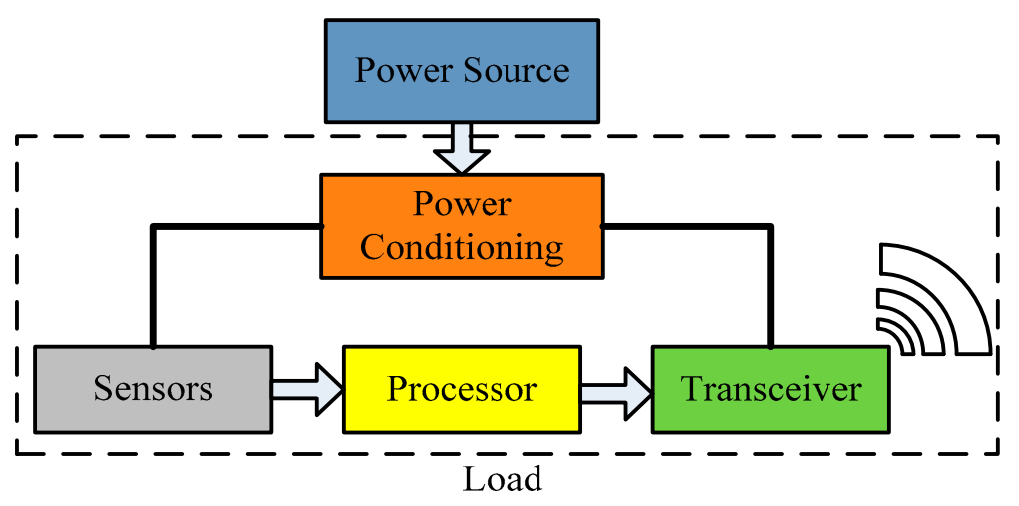

Figure 8. Block diagram of the autonomous sensors [51].

\subsection{Autonomous Sensors Power Source}

Battery and EMEH systems can be the power sources for the ATS $[59,60]$. The battery is an easy solution to be used as a power supply [61]. To avoid replacement of the battery to powering the ATS, the following Equation (18) can be expressed:

$$
E_{b a t}=P_{c, a v} \cdot T_{o p}
$$

where $E_{b a t}$ is the sufficient amount of energy for power in the ATS, $P_{c}$; av is average power demand from the power sources; and $T_{o p}$ is the operation for a lifetime period. To sustain a maintainable process of the ATS when using EMEH approach, the average produced power $\left(P_{g}, a v\right)$ is given by the following Equation (19):

$$
P_{g, a v} \geq P_{c, a v}
$$

where $P_{g}, a v$ is the ambient condition and the efficiency of transducer monitoring. $P_{c, a v}$ is the energy, power, and leakage of storage unit monitoring. The storage element enhances the shifted flow of power to the load $P_{g}<P_{c}$; the arbitrary value will take a long time $T$, to storage $\left(E_{\text {storage }}\right)$, with the following Equation (20):

$$
E_{\text {storage }} \geq \max \left\{\int_{T}\left(P_{c}-P_{g}\right) \cdot d t\right\}
$$

where $P_{c}$ is the consumed power, $P_{g}$ is the instantaneous generated power, and $T$ is the time.

The capacitor, supercapacitor, and rechargeable batteries are used as storage devices in the EMEH system $[62,63]$. The capacitor is one of the elements of the EMEH system for storage [64]. The advantage of the capacitor is availability and low cost. However, a drawback of the capacitor is that it is not suitable for the EMEH system in terms of power density (poor) and also takes a long time to charge and discharge. On the other hand, minor internal impedance and higher lifetimes (in terms of the number of charging/discharge cycles) are indicated as the merit of the supercapacitor $[65,66]$. Nevertheless, supercapacitors are able to accurately count the amount of residual energy such as charging and discharging capacity and states of energy density (i.e., upper or lower). The drawback of the supercapacitor has a much higher cost per energy unit. However, various problems are associated with batteries, when used as a power supply for autonomous sensors, especially in remote areas. Some of these limitations are: size, poor storage capacity, and limited lifecycles [67]. A typical graph of the power density and energy density of the capacitor, supercapacitor, and storage unit batteries is shown in Figure 9. 


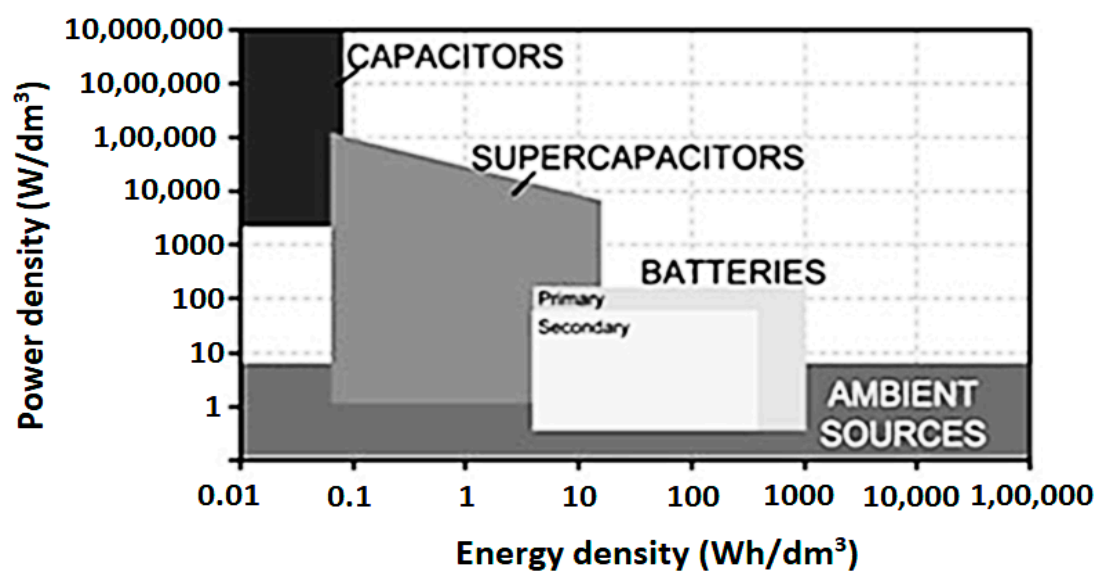

Figure 9. Power density and energy density of capacitor, supercapacitor, and batteries [51].

On the other hand, the ATS is able to run through harvest energy from the ambient sources without or with little maintenance [68-70]. The EMEH transducer, energy conditioning circuit, and energy storage are required to run ATS from ambient energy sources, as shown in Figure 10. However, the drawback of this system is the complexity of the circuit model. Therefore, a vibration-based EMEH system has been proposed to overcome the hurdles in the automatic running of the system.

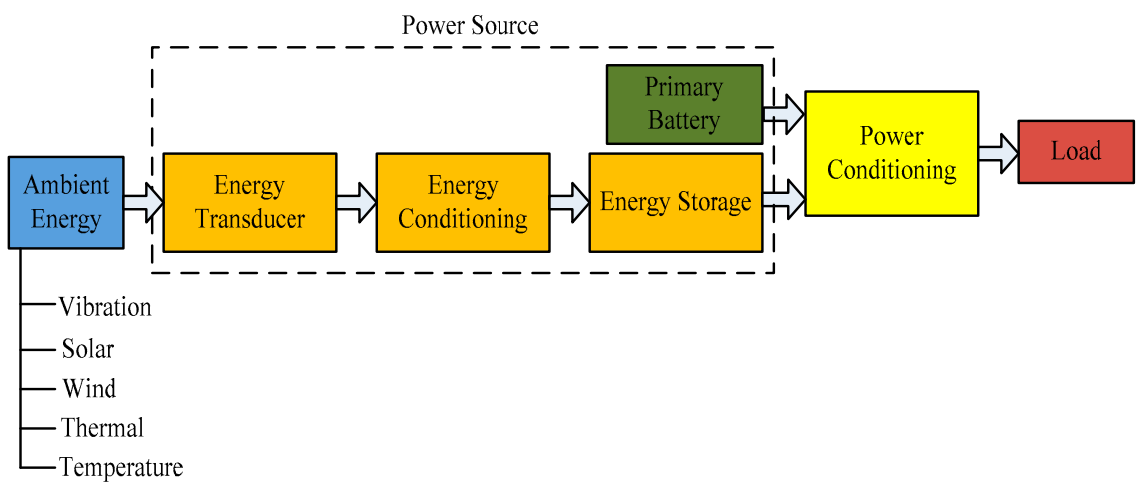

Figure 10. Block diagram power supply source of an ATS.

\subsection{Autonomous Sensor in Electromagnetic Energy Harvesting Systems}

ATS plays an important role to harvest energy from natural sources, and it works efficiently without the need for batteries [50,71]. Usually, this system is user-friendly and can operate the process in the EMEH system easily. The system is developed based on maximum performance as maximum energy can be harvested from environmental sources [72,73]. However, the drawback of ATS in the EMEH system can work only when the ambient sources are available. Therefore, the advantage to use ATS in the EMEH system is their lifetime, storage capability, charging, and discharging performances are unlimited [74]. The block diagram of an autonomous harvesting system (AHS) is shown in Figure 11. The AHS consists of an EH module (EHM), an energy converter module (ECM), and an energy dissipation module (EDM). The EH time interval can be addressed by the following Equation (21):

$$
E_{H}\left(t_{1}, t_{2}\right)=\int_{t_{1}}^{t_{2}} P_{H}(t) d t
$$


where $P_{H}(t)$ is power over time, $t$ is the time, and $E_{H}$ is the energy harvesting. The merit of this system requires only ECM. Equation (22) describes the efficiency of energy transfer from the harvesting module to the EDM:

$$
E_{D}\left(t_{1}, t_{2}\right)<=\int_{t_{1}}^{t_{2}} P_{H}(t) \cdot \eta(u, i) d t
$$

where $\eta(u, i)$ is a nonlinear efficiency coefficient of the ECM, $u(t)$ is voltage, and $u(i)$ is current.

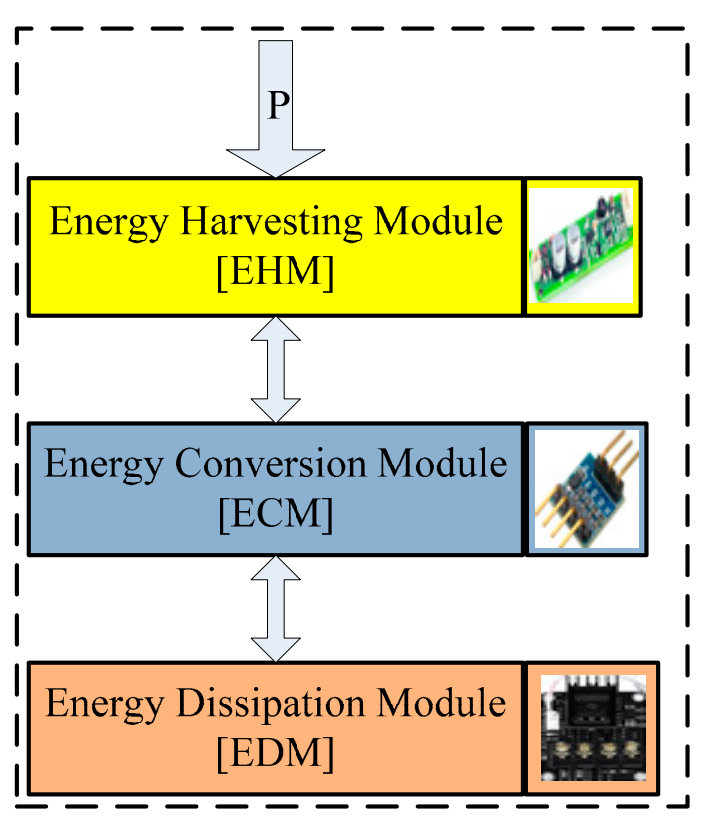

Figure 11. Block diagram of an autonomous harvesting system [75].

\subsection{Autonomous Sensor in Hybrid Electromagnetic Energy Harvesting Systems}

One of the most popular conventional types of EMEH systems is the autonomous hybrid $[76,77]$. They use a rechargeable battery and ultra-capacitor as a storage device, and they collect energy to operate the system $[78,79]$. The advantage of this system is a long lifetime and high storage capacity due to its small size [80]. The performance of energy management and controlling system is faster in terms of rising and settling time. However, the limitation of this system is that it spends more energy than harvested from natural sources because of the system using a secondary battery to store harvested energy [81]. Therefore, to overcome this problem, a supercapacitor can be used to replace the battery. The block diagram of an autonomous hybrid EH (ATHEH) system is shown in Figure 12.

The system consists of three modules such as (EHM, ECM, and EDM), and an energy storage module (ESM). The following Equations (23) and (24) show finite time interval for the ATHEH system [82]:

$$
\int_{t_{1}}^{t_{2}} P_{H}(t) d t \geq \rho\left(t_{2}-t_{1}\right)-\sigma_{1}
$$

where $P_{H}(t)$ is an applicable source in the ATHEH system and $\left(t_{2}-t_{1}\right)$ real-time interval.

$$
\int_{t_{1}}^{t_{2}} P_{H}(t) d t \leq \rho\left(t_{2}-t_{1}\right)+\sigma_{2}
$$


where $P_{H}(t)$ is the harvested power of ambient sources, $\sigma_{1}$ and $\sigma_{2}$ are the energy storage capacity coefficients, and $\rho$ is the power density. The energy storage capacity of the ATHEH system is shown by the following Equations (25) and (26):

$$
\begin{gathered}
E_{\theta_{L}} \leq E_{S}(t) \leq E_{C} \\
E_{C} \geq \sigma_{1}+\sigma_{2}
\end{gathered}
$$

where $E_{C}$ is the energy storage capacity in the supercapacitor or rechargeable battery, $E_{S}$ is the energy storage, and $E_{\theta_{L}}$ is the limit threshold of energy. An optimal energy storage device in the ATHEH system can be expressed by the following Equations (27) and (28):

$$
\begin{gathered}
\int_{t_{1}}^{t_{2}} \frac{P_{D}(t)}{\eta_{2}(t)} d t \leq \int_{t_{1}}^{t_{2}} P_{H}(t) \eta_{1}(t) d t+E_{S} \\
\int_{t_{1}}^{t_{2}} \frac{P_{D}(t)}{\eta_{2}(t)} d t \leq \int_{t_{1}}^{t_{2}} P_{H}(t) \eta_{1}(t) d t+E_{S}-\int_{t_{1}}^{t_{2}} P_{L}(t) d t
\end{gathered}
$$

where $P_{D}$ is the waste power, and $\sigma_{1}$ and $\sigma_{2}$ are the coefficients of the ECM1 and ECM2 correspondingly. The EHM $\left(\eta_{1}\right)$ and $\operatorname{EDM}\left(\eta_{2}\right)$ present the efficiency voltage and current of the system operating point.

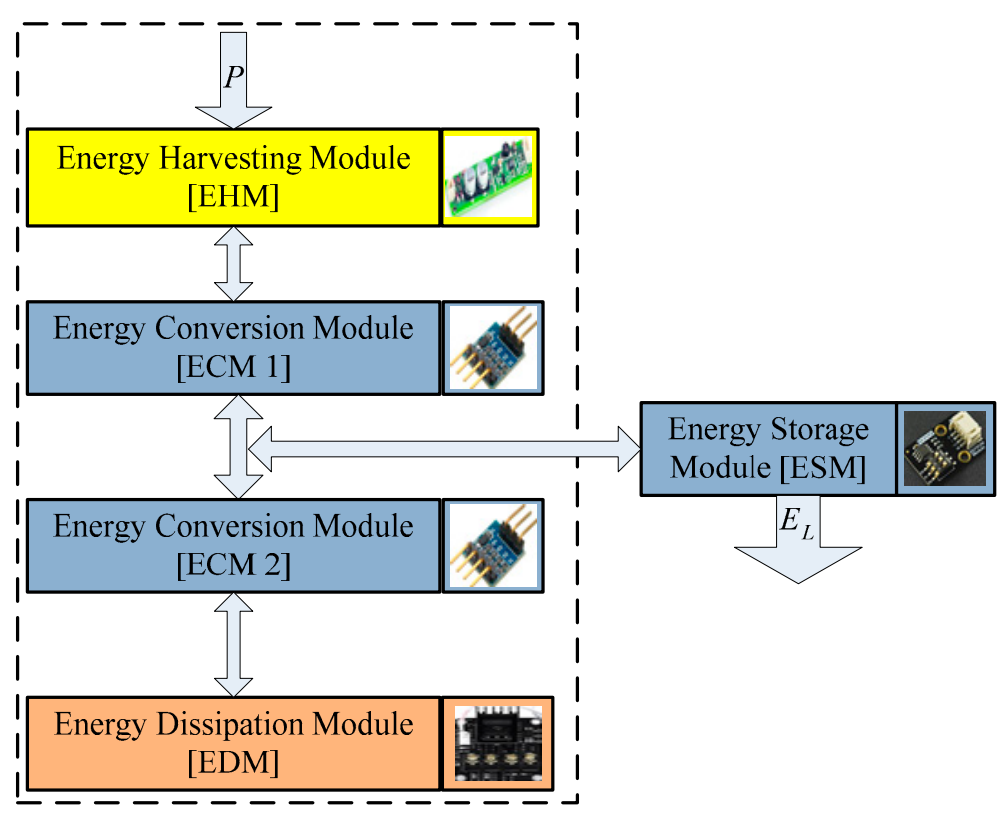

Figure 12. Block diagram of autonomous hybrid electromagnetic energy harvesting system [75].

\subsection{Autonomous Sensors Electromagnetic Energy Harvesting Systems with Radio Frequency}

One of the most largely utilized radio frequency $\mathrm{EH}(\mathrm{RFEH})$ systems for power ATS has addressed many researchers [83-85]. The advantage of the RFEH system from ambient sources is power density is high $[86,87]$. The RFEH system consists of an antenna, impedance matching, filters, and a rectifier, which is shown in Figure 13. To harvest energy from an RF signal, an antenna is required [88].

The equivalent circuit model of an antenna is shown in Figure 14. Where $S$ is the power density, $P_{A V}$ is the available power that the antenna can supply to a matched load, $A_{e}$ is the antenna's effective field, $R_{S}$ is radiation resistance, $R_{\text {loss }}$ is the loss resistance, and $X_{\text {ant }}$ is the reactive part. 


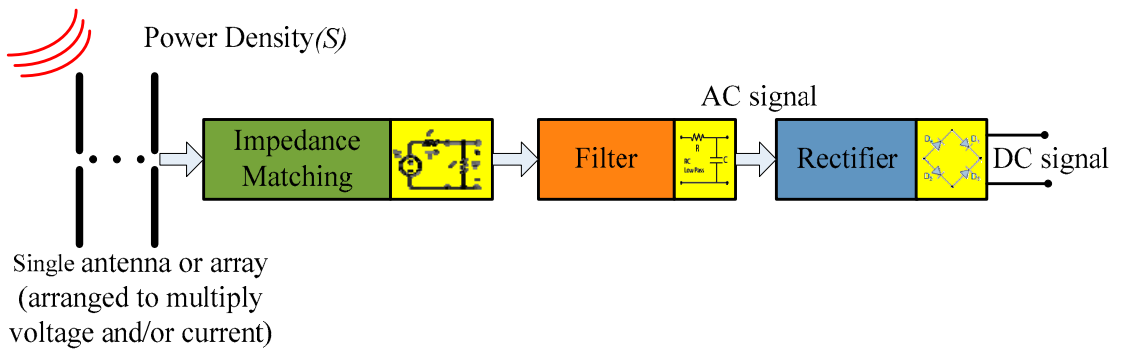

Figure 13. Block diagram of radio frequency energy harvesting system.

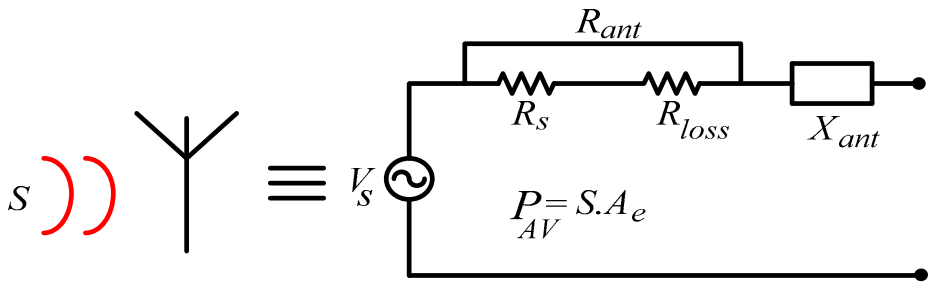

Figure 14. Equivalent electrical model for an antenna [20]. Reprinted from ref. [20].

In this EMEH system where the battery is used as a storage source of energy, on the other hand, the harvesting device such as a transducer plays the main role. The energy controlling sector plays an essential role in such a system to manage the discharging capacity of the battery and increase the lifetime of the battery [89-91]. The advantage of this system is a model with two kinds of battery storage such as a primary and secondary battery. Usually, the load can run using primary battery storage, on the other hand, secondary also works as a backup of a load [92]. Hence, the load can work suitably. However, the drawback of such a system is it is not convenient for the environment EH system due to the limited lifetime of battery storage. The system is also costly in terms of replacing the battery and requires more storage as a backup for a load. Therefore, an automated EMEH system can be utilized to overcome such a problem. Figure 15 shows an EMEH system using the additional battery. The system consists of the components EHM, ECM, EDM, ESM, a primary (non-chargeable) battery module (BM), and a power multiplexer (PM). The following equation shows the additional battery energy storage system.

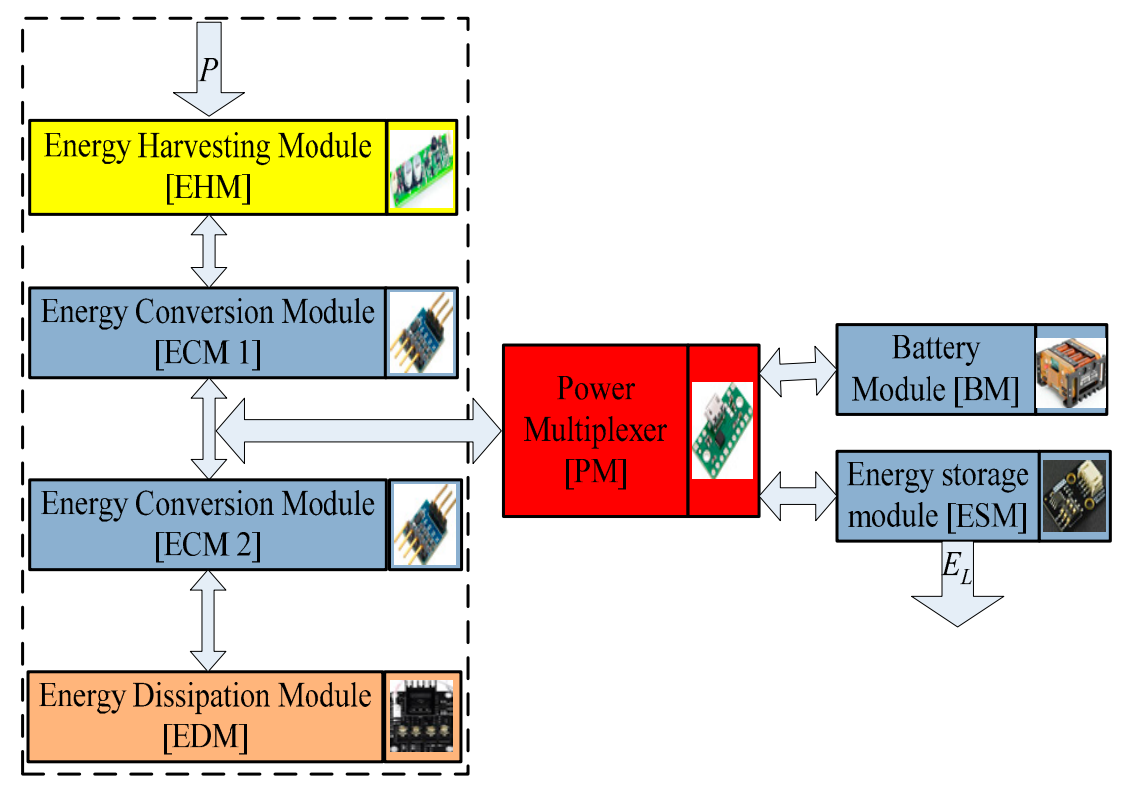

Figure 15. Electromagnetic energy harvesting system using an additional battery [75]. 


\section{Power Electronic Technologies in Electromagnetic Energy Harvesting}

This segment describes the characteristics, efficiency, and limitation of power electronic converters EMEH system. The controller mathematical model, formation, and methods are also presented [93-95].

\subsection{A Standard Circuit for Energy-Harvesting}

Usually, the EMEH transducer generates an AC voltage [96,97]. Most of the low power sensors require DC voltage to run micro devices such as WSNs. The general EMEH circuit is contained in a coil array such as sensors, transducer, a full-wave rectifier circuit, low pass filter, and load as shown in Figure 16. The basic principles of the EMEH circuit are that input sources such as a transducer or sensors on both sides are connected in series with a rectifier circuit, and the output of the rectifier is connected with the capacitor, which filters and stores energy $[98,99]$. A nonlinear EMEH and a nonlinear interface circuit are integrated into the device [100-103]. In Figure 17, the equivalent circuit of the nonlinear EMEH system is shown. The structure equivalent to the EMEH transducer circuit is constructed with internal resistance $R_{W}$ and internal inductance $L_{W}$. The nonlinear EMEH system's governing equations can be expressed as Equation (29).

$$
\left\{\begin{array}{c}
M x(t)+C_{m} \dot{x}(t)+k(|x(t)|-S)+\frac{x(t)}{|\dot{x}(t)|} \mu M g+k I(t)=-M \ddot{x}_{b}(t) \\
L_{w} \dot{I}(t)+R_{w} I(t)+V(t)=k \dot{x}(t)
\end{array}\right.
$$

here, $\mu$ is the constant of revolving irritation, $M$ is the mass of the central edge, $C_{M}$ is the damping coefficient, $S$ is the elementary holes between the open ends of the springs and the other part of the exterior edge, and $k$ is the actual stiffness of the springs. The product of the electromechanical coupling of the dynamics of the harvester can be written as:

$$
k I(t)=C_{e} \dot{x}(t)-\frac{k V_{r}}{R_{w}+R_{L}} \operatorname{sgn}(\dot{x}(t))+k r C_{r} \dot{V}_{L}(t) \operatorname{sgn}(\dot{x}(t))
$$

where $\operatorname{sgn}(\cdot)$ is the signum function, $R_{W}$ is the inner resistance, $L_{W}$ is the internal inductance, $t$ is the time, $I(t)$ is similar with $x(t), V_{r}$ is the voltage drop of the rectifier, and $V_{L}$ is the voltage across the controlling capacitor.

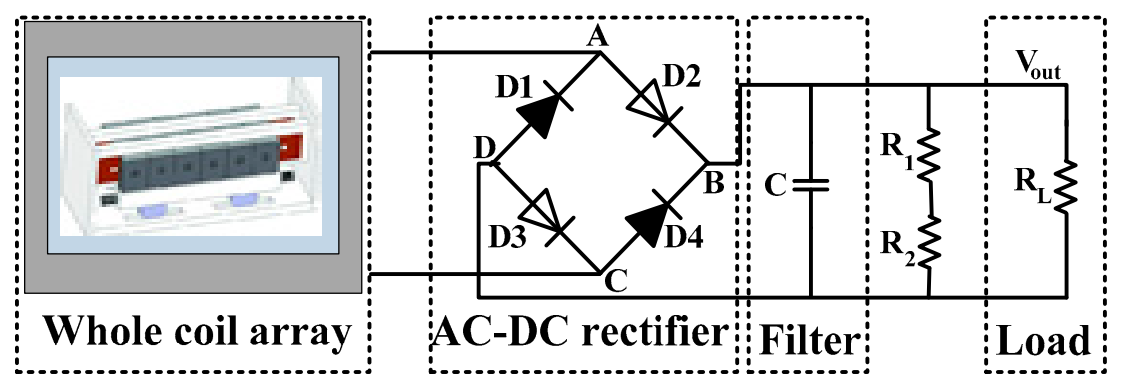

Figure 16. Standard energy-harvesting circuit [28].

The basic principle of the EMEH transducer generates AC voltage with fluctuation and harmonic [104,105]. The rectifier is required to convert AC voltage to DC, and a low pass filter is required to reduce the noise of the rectifier signal. Usually, the performance of the EMEH circuit depends on the outcome of energy conversion between mechanical to electrical through proper impedance matching [106,107]. In [108], the authors indicated a resistive technique for impedance-matching of EMEH. However, the limitation of this technique is old and low conversion efficiency. Therefore, to overcome this problem, synchronous switch harvesting on inductor (SSHI) technique is required. The study in $[109,110]$ addressed a two-stage power management circuit (PMC) for AC to DC converter and DC to DC converter in EMEH. The PMC consists of a rectifier module, buck-boost DC-DC 
converter module, a switch control module, and a charging and discharging module for energy storage devices, as shown in Figure 18. The overall operation principle of the PMC is that the output of the EMEH transducer coil is connected with the input of the full-wave diode bridge rectifier circuit [111,112]. The EMEH transducer's harvester output voltage is rectified and directly linked to the DC-DC converter circuit supply [113]. The NMOS switch is controlled by the pulse produced by the pulse-width modulation (PWM) process. The control circuit consists of a controller, a relational operator, a modulator for PWM, and a generator for sawtooth voltage. The outcomes of the DC-DC converter are connected in parallel with the resistance and storage devices in the capacitor [114]. However, the drawback of this model is lacking efficiency of voltage. The lack of efficiency of voltage is basically the voltage loss in the converter due to the internal resistance of the converter. This loss of efficiency can be reduced by decreasing the internal resistance of the AC-DC converter.

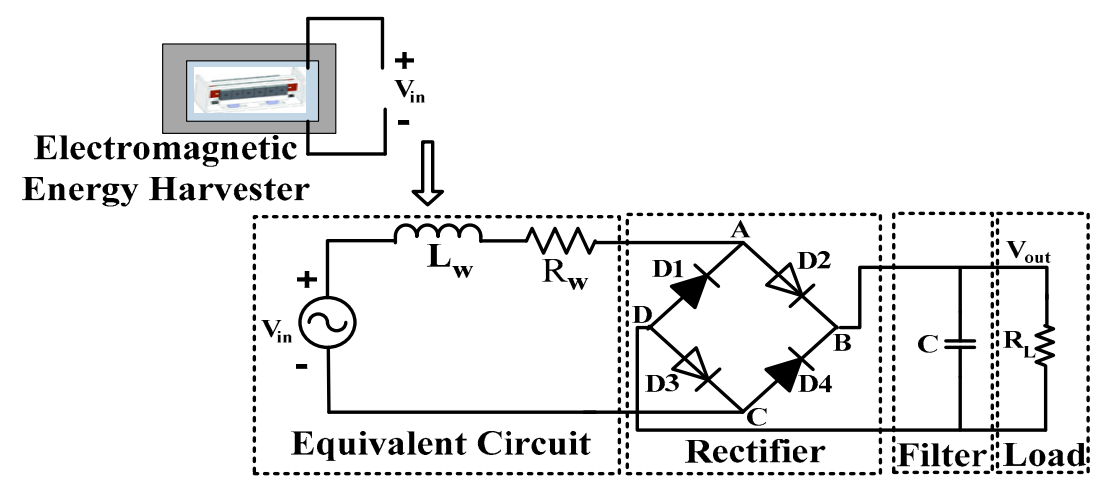

Figure 17. Corresponding symmetric diagram of electromagnetic energy harvesting system [28].

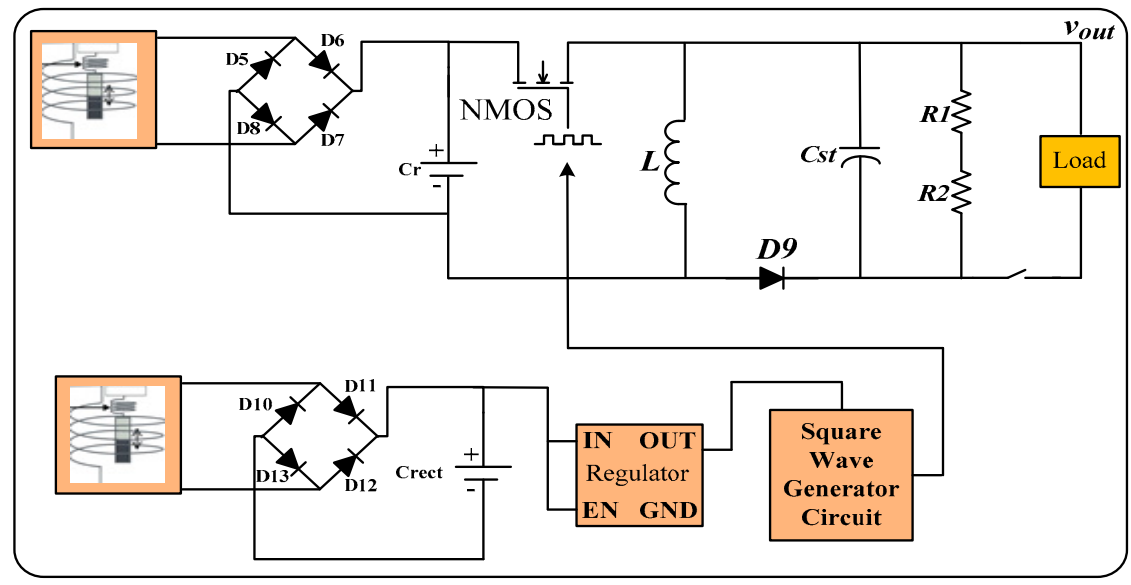

Figure 18. Power management circuit of electromagnetic energy harvester [28].

In $[115,116]$, the authors proposed an EMEH circuit with close loop boost converter switch control through PWM for feedforward and feedback control as shown in Figure 19. The working principle of this model when the output voltage of the rectifier is bigger than the forwarding voltage of the diode and boost converter is that the voltage directly connects to the storage unit (i.e., capacitor, battery, supercapacitor) $[116,117]$. However, the limitation of this model is complex in terms of its need for a mathematical model, and it is also time-consuming and not suitable for low power devices such as EH applications. Therefore, an optimization technique can be utilized to overcome the limitation of this controller model. The system can be expressed by the following equations:

$$
(1-D) T=\frac{V_{1}}{V_{e s}} \frac{R_{2}}{\left(R_{1}+R_{2}\right)} \frac{\left(R_{3}+R_{4}\right)}{R_{4}} \frac{R_{1} C}{\left(1-D_{p}\right) T}
$$




$$
\begin{gathered}
1-D=D^{\prime}=\frac{V_{1}}{V_{e s}} \frac{R_{2}}{\left(R_{1}+R_{2}\right)} \frac{\left(R_{3}+R_{4}\right)}{R_{4}} \frac{R_{1} C}{\left(1-D_{p}\right) T^{2}} \\
D=1-\frac{V_{1}}{V_{e s}} \frac{R_{2}}{\left(R_{1}+R_{2}\right)} \frac{\left(R_{3}+R_{4}\right)}{R_{4}} \frac{R_{1} C}{\left(1-D_{p}\right) T^{2}}
\end{gathered}
$$

where $D$ is the duty ratio, $T$ is the whole period of time, $R$ is the parasitic series resistor, $C$ is the capacitor, $V$ is the voltage, and $V_{e S}$ is the voltage of the energy storage element.

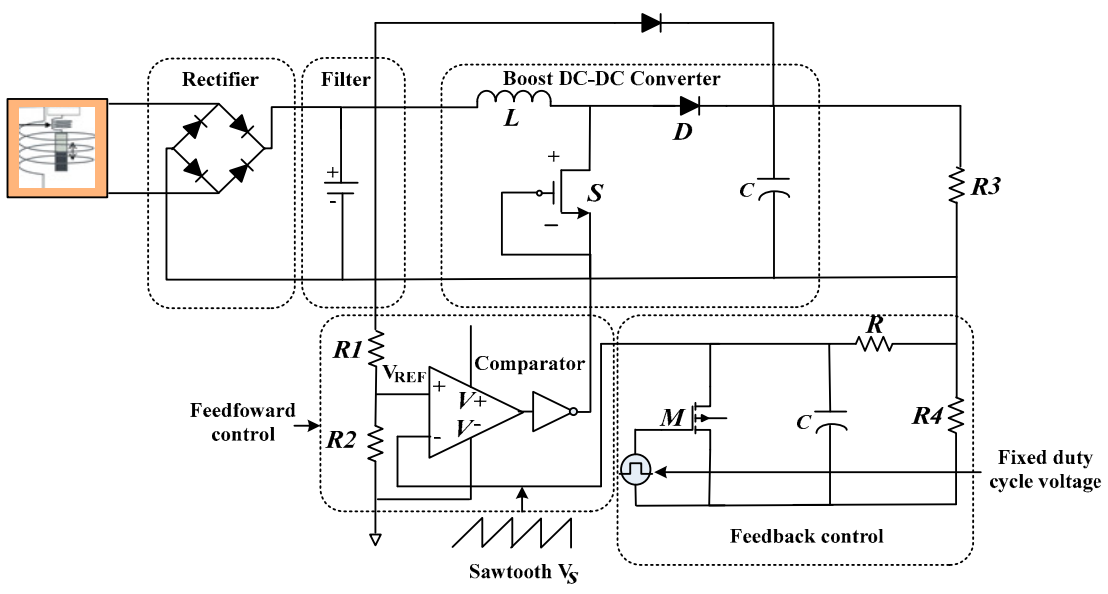

Figure 19. Energy harvesting circuit with boost converter for feedforward and feedback control [115].

In [118], the author proposed a vibration-based EMEH interface circuit. Figure 20 shows the four categories of electrical circuits, used to extract the energy from ambient sources and store the harvesting charge in the EH applications. Figure 20a shows the ordinary EH and energy storage circuit; Figure 20b shows the synchronous electric charge extraction (SECE) circuit; Figure 20c shows the parallel SSHI circuit; and Figure 20d shows the series SSHI circuit [118-120]. However, the drawback of such a circuit for EH application is that the conversion efficiency is poor between mechanical to electrical energy in terms of impedance matching mechanism using SECH and SSHI methods. Therefore, to overcome this problem in the EH system, optimization techniques can be utilized to make the system simple and automated without time-consuming.

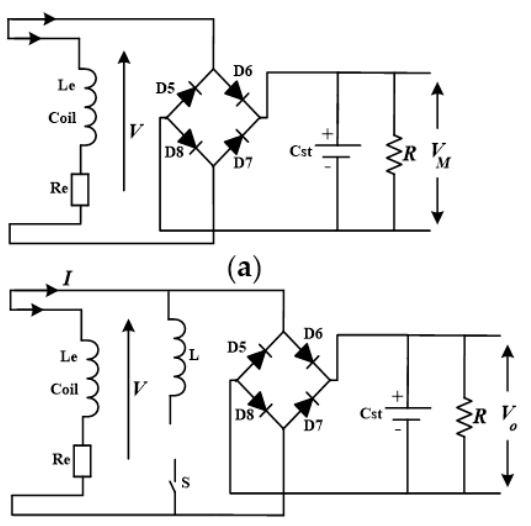

(c)

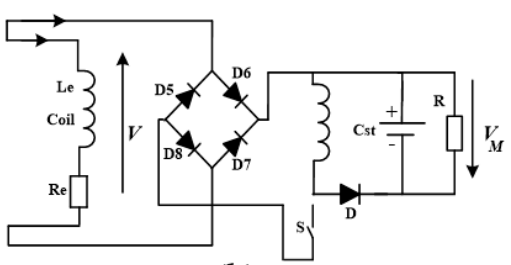

(b)

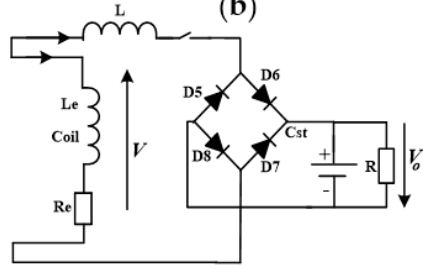

(d)

Figure 20. Conventional vibration-based energy harvesting circuit: (a) standard, (b) SECE, (c) parallel SSHI, and (d) series SSHI circuit [118]. Reprinted with permission from ref. [118]. Copyright 2015 Elsevier. 
The traditional vibration-based EMEH interface circuit and optimal harvested power are derived by the following equation:

$$
\frac{P_{h}}{\left(\frac{M^{2} \cdot|y|^{2}}{D}\right)}=\frac{a_{N}^{2} \cdot R_{N} \cdot\left(\frac{\pi}{2}+\frac{1}{R_{N}}\right)^{2}}{2 \cdot\left[\left(\frac{\pi}{2}+\frac{1}{R_{N}}\right)^{2}+\alpha_{N}^{2} \cdot R_{N}\right]^{2}}
$$

where $P_{h}$ is the input resonant power, $\frac{M^{2} \cdot|y|^{2}}{D}$ is the reference power, and $a N$ and $R_{N}$ are the electromagnetic harvester.

In $[2,121]$, the authors described the block of spring, mass, damper for the EMEH system as shown in Figure 21. This is an analogous system generally used for vibrationbased EH systems. The system is important for energy conversion from mechanical to electrical and vice versa.

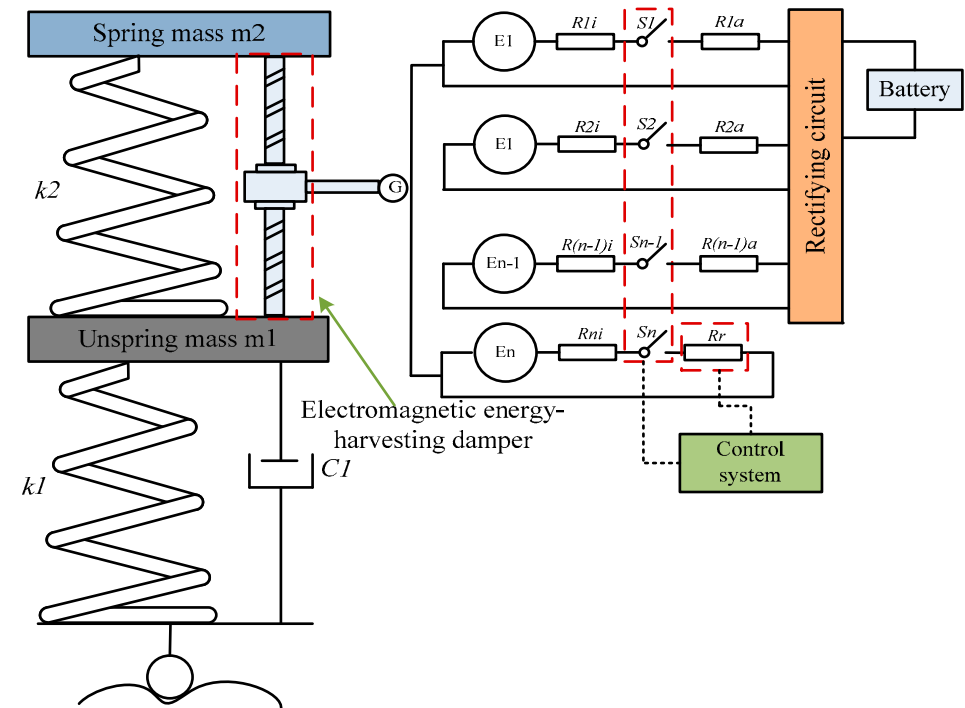

(a)

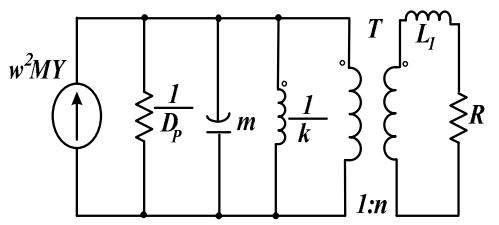

(b)

Figure 21. Block diagram of the spring, mass, damping method for EMEH system (a,b). Schematic of the spring, mass, damping system $[93,121]$.

The study reported in [122] indicated the n-stage rectifier circuit model for the EMEH system also shown in Figure 22. The authors also proposed multiple diodes connected in a series to increase the power of the harvesting signal. However, the limitation of this model is the bias voltage of the diode. Therefore, the Schottky diode can be used to overcome this problem due to its low bias voltage.

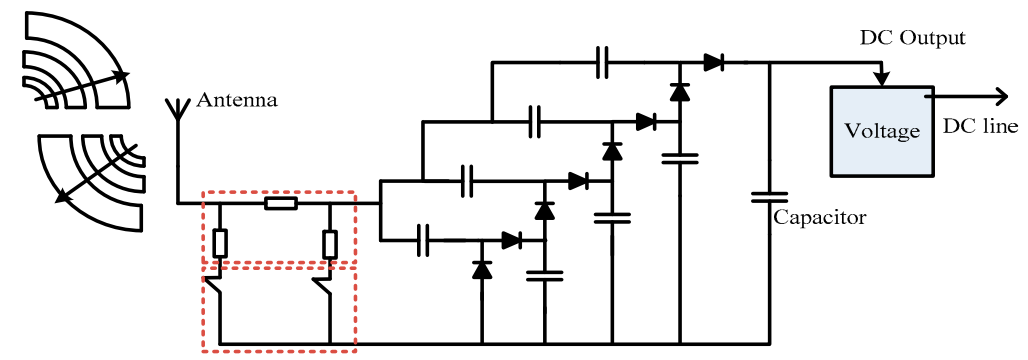

Figure 22. n-stage rectifier circuit model of electromagnetic energy harvesting system [122].

The authors in [123] suggested an electromagnetic damper cum energy harvester (EMDEH) circuit model as shown in Figure 23. The basic principle of this circuit model 
compared to other $\mathrm{EH}$ is, it proposes a resistor circuit, which includes a full-wave bridge rectifier. The presence of this resistor circuit provides a basis for evaluating the output of the functional EH device, which inevitably includes power loss and input resistance variation [124,125]. However, the drawback of this model is, it is used in many electronic components, and those components have their own biasing voltage that is not suitable for the low power model [126]. Therefore, a simple circuit model with low biasing electrical components such as a low power resistor, Schottky diode is utilized to overcome the issue.

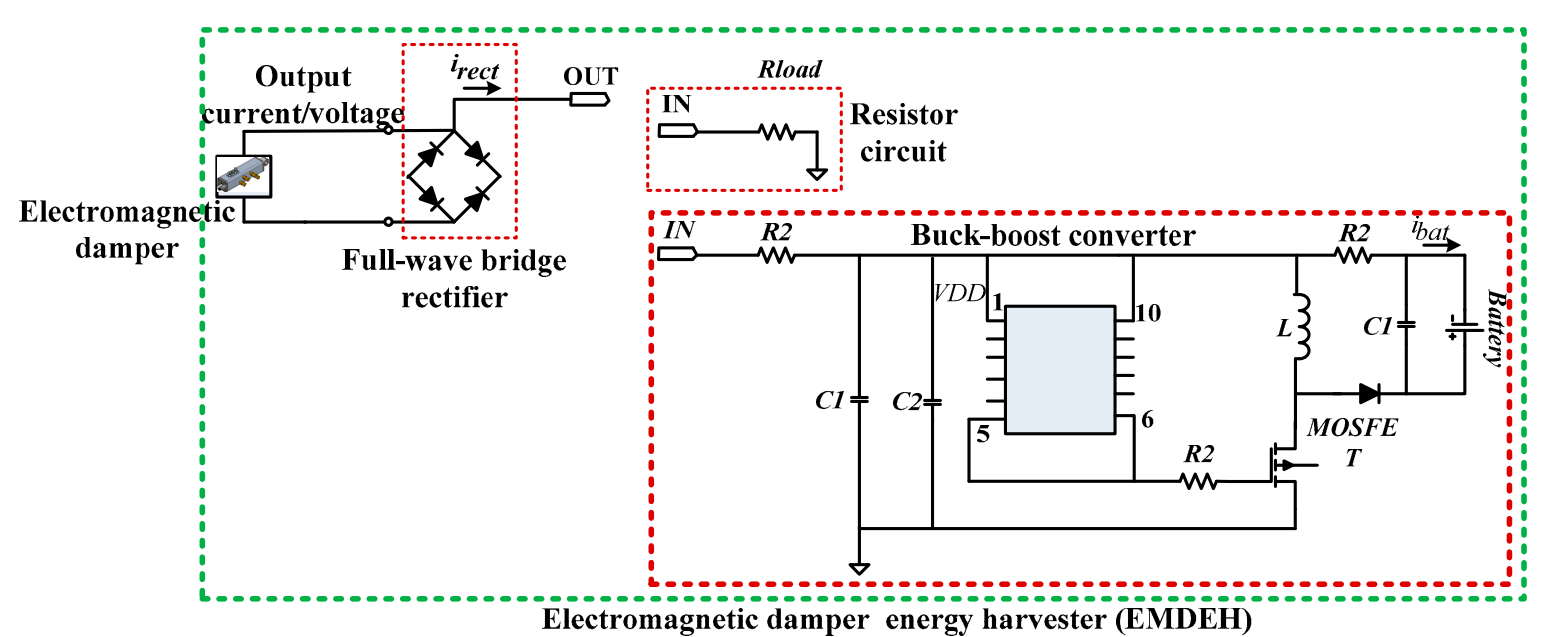

Figure 23. Symmetry of EMDEH in energy harvesting for vibration control [124].

The authors in [127-129] reported an EMEH circuit based on active and passive mode, shown in Figure 24. Figure 24a shows the passive mode EH circuit model, and Figure 24b shows the active mode EH circuit model. The study in [128] presented the phenomenon of circuits namely the passive and active techniques' components. The authors referred to an active technique in [127] and selected its components such as MOSFET, thyristor, and transistors to design the EH circuit. The authors also proposed EH through active components that are suitable for ultra-low-power application in terms of low biasing voltage. In [129], the authors suggested a passive technique to design an EH circuit model. However, the passive technique is not suitable for low power applications, especially in the EH system, to increase the low input voltage in terms of high biasing voltage.

\subsection{Converter Technology for Electromagnetic Energy Harvesting System}

Generally, electronic converters topology has four classifications, such as i. AC to AC, ii. AC to DC, iii. DC to DC, and iv. DC to AC $[130,131]$. Many applications have already made use of these converters. The AC to DC converters convert AC waveform to DC, which is suitable for EMEH transducer. The basic application of DC to DC converters is to boost up DC to DC voltage of vibration, wind, solar PV that is suitable for low power $\mathrm{EH}$ applications. The DC to AC converter is utilized to convert DC signal to AC waveform, which is suitable for thermoelectric EH application. With reference to Figures 1 and 2, the different topologies of power converters are explained below:

\subsubsection{AC to DC Converter}

AC-DC converters transform the alternating current to a constant DC output voltage. Small-, medium-, and high-power applications are all possible with these converters. Uncontrolled rectifiers, also known as diode rectifiers or unidirectional AC-DC converters, consist of diodes. On the other hand, a diode rectifier causes significant input current distortion. As a result, a significant amount of effort is required to develop a filter that reduces ripple. Figure 25 shows an AC-DC converter with multi-input, bridgeless resonantcircuit design concepts [130]. The conversion of low amplitude voltages (alternating) from 
multiple electromagnetic-reed (EMR) generators, to a controlled DC output voltage, is also shown in Figure 25. Without the use of a diode bridge, the topology is capable of interfacing many, individual, input sources. Voltages with very low amplitude may be scaled up to moderately high voltage. Multiple inductive sources can be controlled with this topology. In the EMR generator, $N$ is the number assigned to each inductive source. A resonant-inductor, diode, and several MOSFET-capacitor-bridges make up the multi-input circuit. Each input source is wired into one of two MOSFET-capacitor-bridges $(M(N) r 1$, $C(N) r 1$, and $M(N) r 2, C(N) r 2)$ sharing a resonant inductor with a diode.
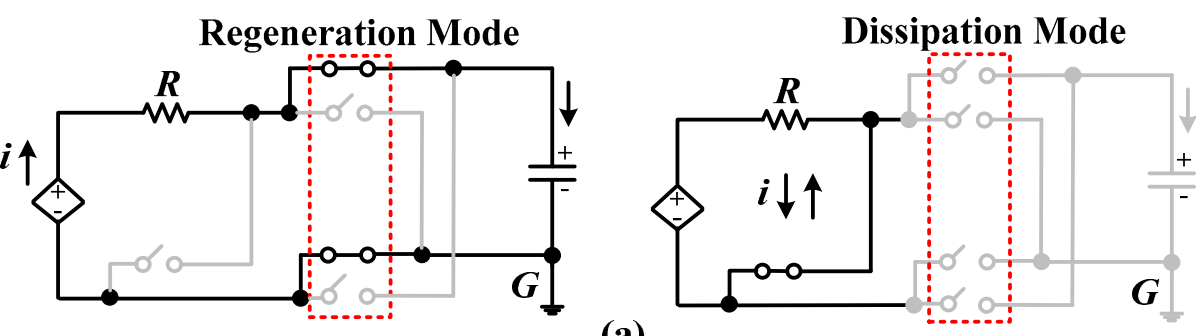

(a)

Regeneration Mode

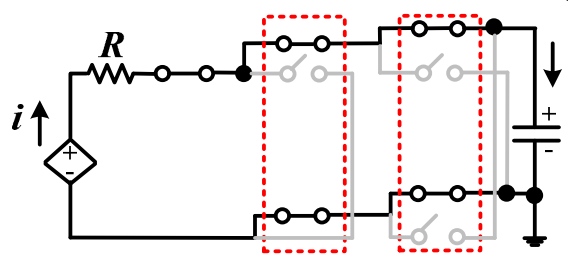

$K|y|>e_{c}$

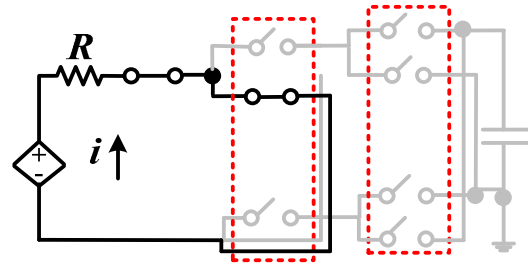

$K|y|>e_{c}$

Drive Mode

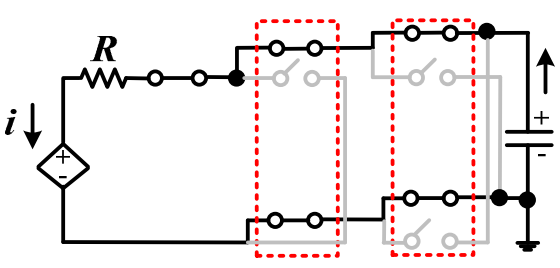

$e_{c} \geq K|y|$

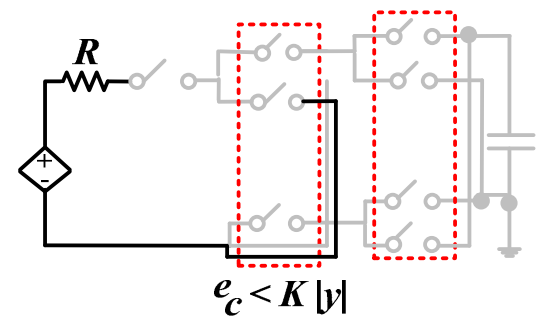

Brake Mode
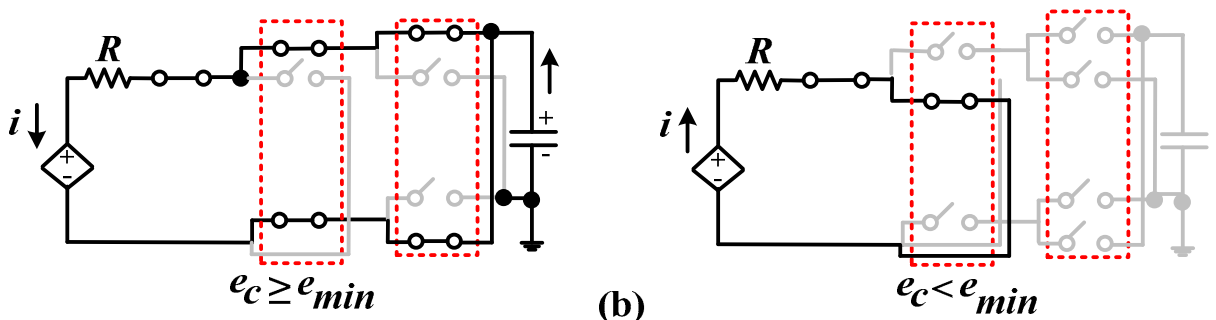

Figure 24. Operation modes and the associated electrical circuits for the (a) passive EMEH system; (b) active EMEH system [127]. Reprinted with permission from Hasheminejad, Rabiee and Markazi (2018). Copyright 2018 ASCE Library.

In the literature, a variety of multilevel converter topologies with various features have been defined [131-133]. Figure 26 shows the classification of a multilevel AC-DC converter. 


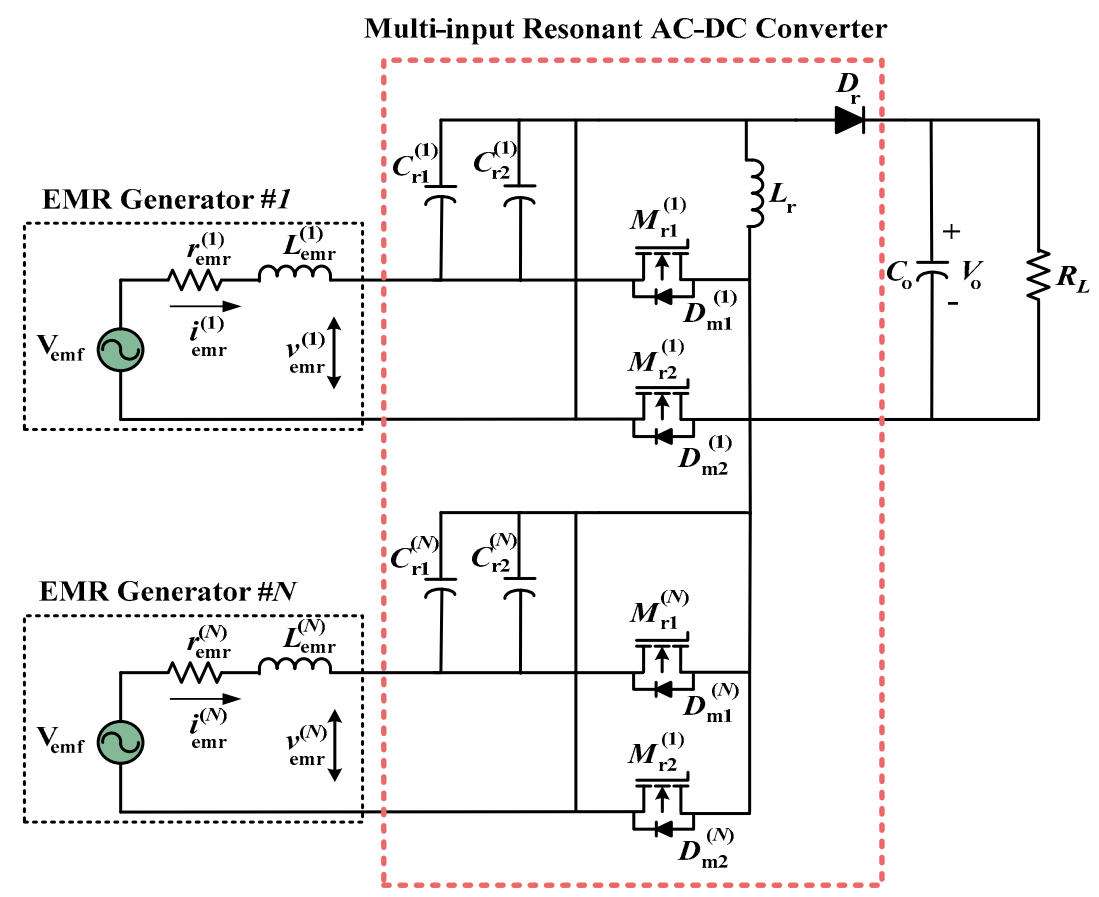

Figure 25. Multi-channel of EMR generators system [130]. Reprinted with permission from ref. [130]. Copyright 2015 IEEE.

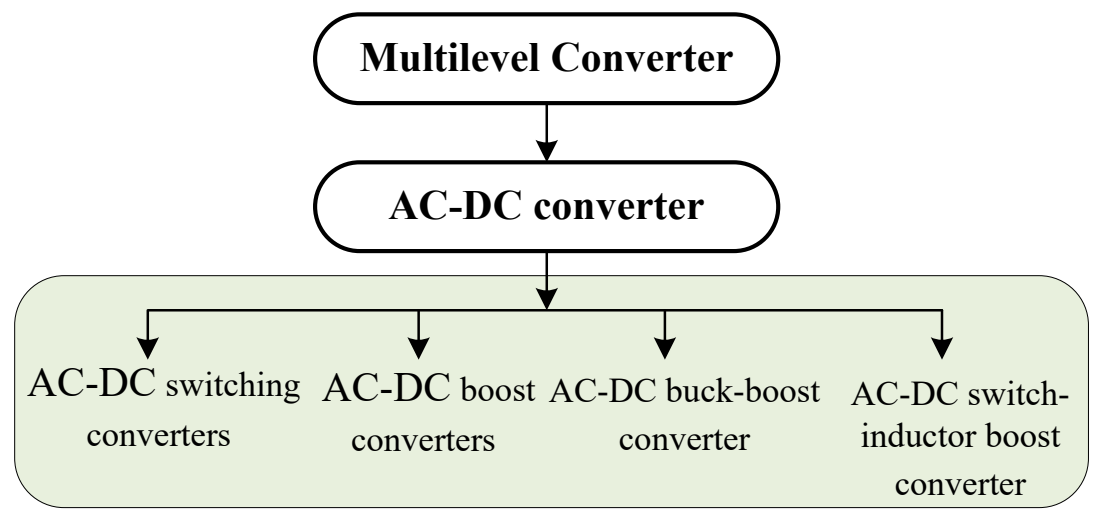

Figure 26. Classification of multilevel converter.

\subsubsection{AC to DC Switching Converter}

In switch-mode power supply circuits, $\mathrm{AC}$ to DC converters are used to transform AC voltage to DC output (controlled). The important characteristics are i. input voltage scale, ii. maximal input current, iii. DC output-voltage, iv. maximal peak current, and v. continuous current of the load. The work in [131] reported a direct AC-DC converter that is suitable for low voltage $\mathrm{EH}$ applications.

\subsubsection{AC to DC Boost and Buck-Boost Converter}

A boost-converter is a step-up that generates a higher output voltage as compared to the input voltage. There are two states of operation for boost-converters: ON and OFF, and share the same characteristics as the buck-converter. A step-down or step-up converter can be used with a buck-boost. When the service period is less than 0.5 , the converter behaves like a buck-converter. Whereas, it acts like a boost-converter when the service cycle is set between 0.5 and 1 . The study in [132] reported that i. AC-DC boost converter and ii. AC-DC buck-boost converters are favorites for power processing circuits for (a) electromagnetic, (b) electrostatic and (c) piezoelectric inertial energy harvesting. Figure 27a 
depicts the two boost-converter sub-circuits: one that produces the upper half of the output voltage with positive generator voltage, and the other that generates the lower half with negative generator voltage. The parasitic diodes of the MOSFETS cannot be forward biased because the generator voltage is too low. Figure $27 \mathrm{~b}$ shows the buck converter that was first investigated because it was the initial circuit that easily converted high to low voltage.

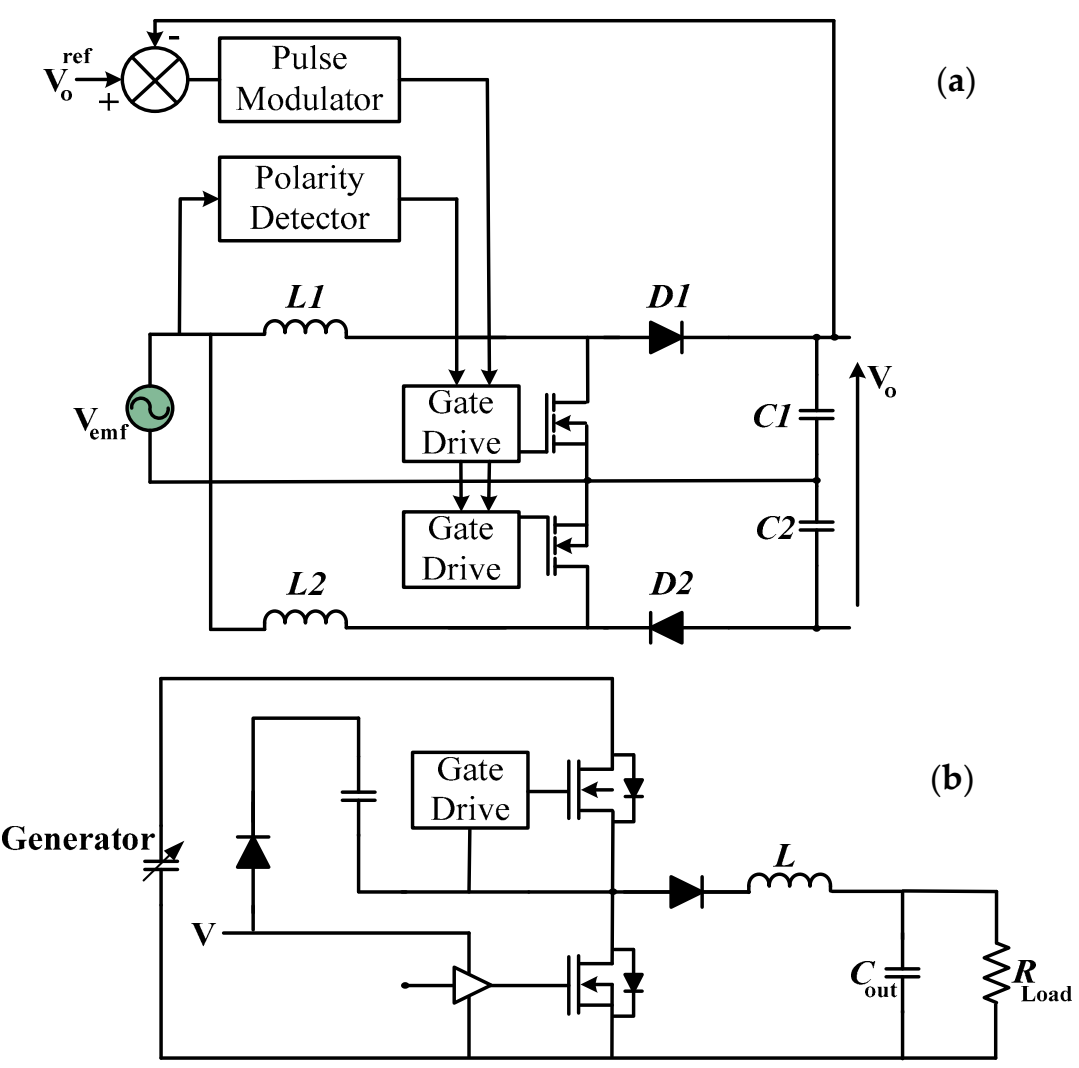

Figure 27. A double-split boost converter (a), buck converter (b) [132]. Reprinted with permission from ref. [132]. Copyright 2007 Springer Nature.

\subsubsection{AC to DC Switch-Inductor Boost Converter}

For effective EH, with the low voltage inertial micro generators, a direct AC-DC boost converter is used. To avoid using a front-end bridge rectifier, the converter makes use of MOSFETs' bidirectional current-conduction capability. It provides a resistive load, and the mode of operation is discontinuous. The distinct topologies of active AC-DC switch converters are employed in EH applications such as i. dual-capacitor boost-converter, ii. dual-capacitor buck-boost converter, iii. boost-converter secondary switches, and iv. bridgeless boost rectifier as shown in Figure 28 [133]. For separate +ve and -ve voltage conductions, both bidirectional switches and dual-capacitors are used in such topologies, or parallel DC-DC converters (two) are used. Due to the low frequency in micro-generators, dual-capacitor topologies are used as shown in Figure 28a,b, which required large enough to repress ripple-voltage below the desired amount. Besides, the alternative of dualcapacitors is two synchronous MOSFETs as shown in Figure 28c. Figure 28d shows a bridgeless boost-rectifier that combines in a very special way a boost with buck-boost converters. With +ve input-voltage, the circuitry works in boost mode, M1 is switched on, and diode (D1) is reverse-biased. Table 2 shows the comparison of different AC-DC converter topologies famous in the EH system. 

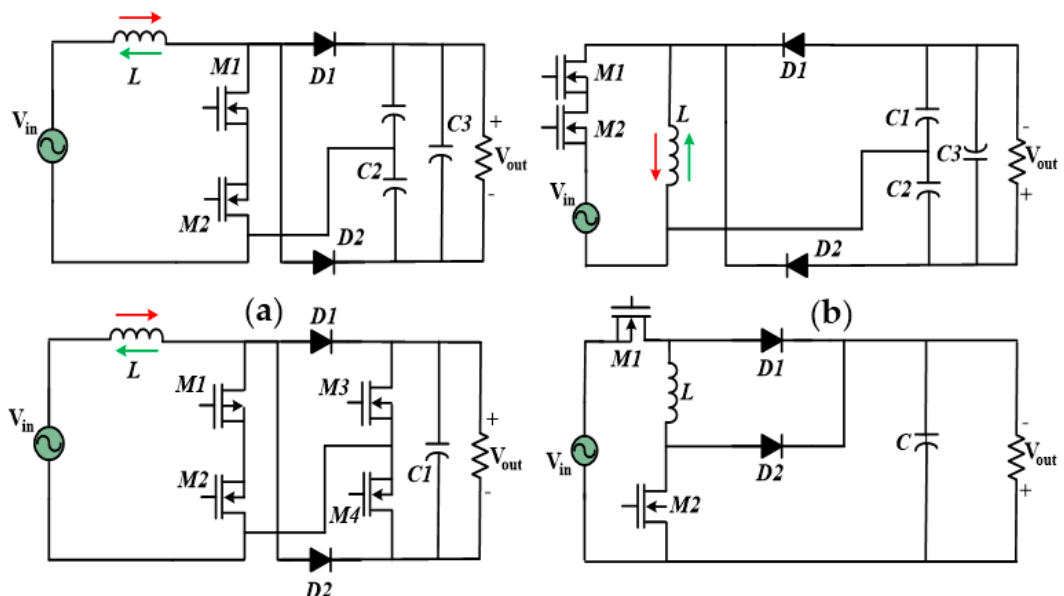

(c)

(d)

Figure 28. AC to DC switch converter topologies: (a) dual capacitor boost converter, (b) dual capacitor buck-boost converter, (c) boost converter with secondary switches, and (d) bridgeless boost-rectifier [133].

Table 2. Comparison of different AC-DC converters topology for energy harvesting.

\begin{tabular}{|c|c|c|c|c|c|c|c|}
\hline Refs. & Topology & Advantages & Disadvantages & Frequency & Load & Efficiency (\%) & Applications \\
\hline [130] & $\begin{array}{c}\text { AC-DC } \\
\text { converter }\end{array}$ & $\begin{array}{l}\text { High efficiency } \\
\text { with low } \\
\text { frequency }\end{array}$ & $\begin{array}{c}\text { Not } \\
\text { recommended } \\
\text { for use at high } \\
\text { power levels }\end{array}$ & Low & Resistive & $86.3 \%$ & $\mathrm{EH}$ \\
\hline [131] & $\begin{array}{l}\text { AC-DC } \\
\text { switching } \\
\text { converter }\end{array}$ & $\begin{array}{l}\text { Suitability for } \\
\text { low power } \\
\text { micro devices }\end{array}$ & $\begin{array}{l}\text {-Biasing } \\
\text { voltage of } \\
\text { diode high } \\
\text {-Difficult to } \\
\text { overcome low } \\
\text { input voltage }\end{array}$ & $50-\mathrm{kHz}$ & Resistive & High & $\mathrm{EH}$ \\
\hline [132] & $\begin{array}{l}\text { AC-DC boost } \\
\text { and } \\
\text { buck-boost } \\
\text { converter }\end{array}$ & $\begin{array}{l}\text { Capable to i. } \\
\text { step-up and ii. } \\
\text { step-down } \\
\text { voltage levels }\end{array}$ & $\begin{array}{l}\text {-Complex } \\
\text { design } \\
\text {-Difficult to } \\
\text { implement }\end{array}$ & $50-\mathrm{kHz}$ & Resistive & High & $\mathrm{EH}$ \\
\hline [133] & $\begin{array}{l}\text { AC-DC switch- } \\
\text { inductor boost } \\
\text { converter }\end{array}$ & $\begin{array}{l}\text {-Small size } \\
\text {-Easy to } \\
\text { implement } \\
\text {-Low cost }\end{array}$ & $\begin{array}{l}\text {-High noise } \\
\text {-Low power } \\
\text { capability }\end{array}$ & $50-\mathrm{kHz}$ & Resistive & $71 \%$ & $\mathrm{EH}$ \\
\hline
\end{tabular}

\subsubsection{DC to DC Converter}

A single-direction DC-DC converter is one of the most common power electronic converters for EMEH applications [113-115]. The output voltage magnitude of such a converter increases or decreases in comparison to the input voltage magnitude from ambient sources. The DC-DC converter has weak voltage-regulation with an inadequate active response when operated in an open-loop, so it is used as a closed-loop feedback control system for output voltage regulation. To achieve the best output voltage from the controller, some researchers suggest switching the converter on and off (duty cycle). For switching control of the MOSFETs in the DC-DC converter circuitry, high frequency PWM is the best option to regulate power flow [115]. The benefits of single-phase DC-DC converters include the need for only one MOSFET to be switched, low losses, and suitability for EMEH applications. Based on their operating modes, DC-DC converters can be divided into three categories: (i) linear mode, (ii) hard switching mode, and (iii) soft-switching mode converter as shown in Figure 29. The switching mode converters are categorized into 
two groups namely non-isolated and isolated-converters. The non-isolated topologies are classified into four groups such as (a) boost, (b) buck, (c) buck/boost, and (d) Cuk converter, which consists of a diode, inductors, capacitors, and a switch as shown in Figure 30 [134]. They can produce satisfactory outcomes by reducing noise, simplifying the process, and providing a quick response with good regulation. However, they have some drawbacks, such as the fact that they dissipate power under any working conditions, resulting in low performance.

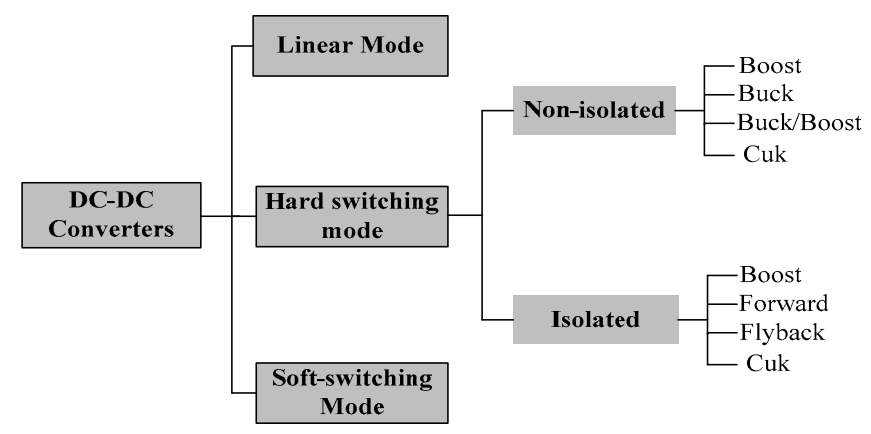

Figure 29. Classification of DC-DC converters.

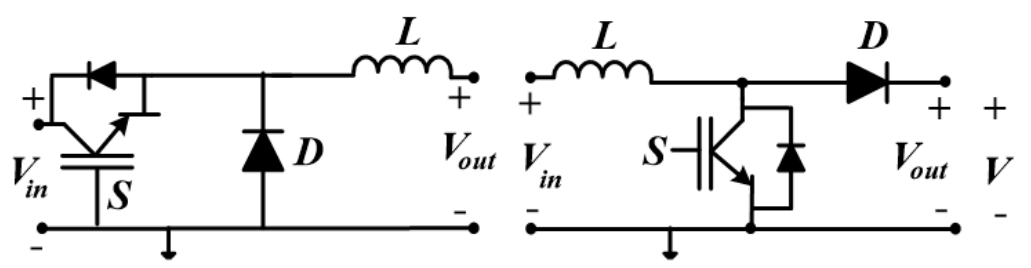

(a)

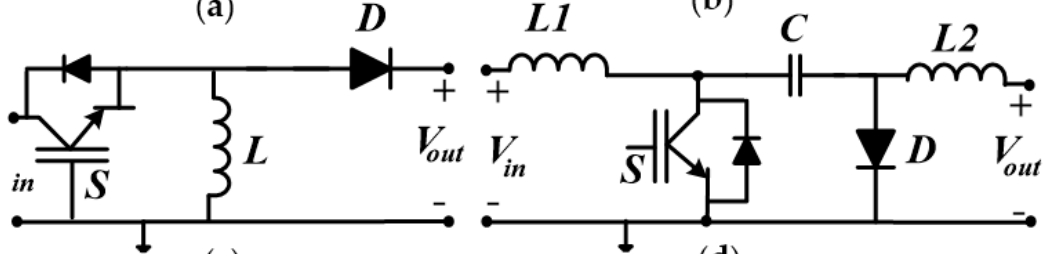

(c)

(d)

Figure 30. Numerous conventional non-isolated DC-DC converters: (a) buck, (b) boost, (c) buckboost, and (d) Cuk [134].

On the other hand, the isolated topologies are classified into four types such as boost, forward, flyback, and full-bridge converter, which consists of a transformer or coupled inductor as shown in Figure 31 [134]. These converters can solve the problem of unstable low power sources in the EMEH system [135]. Vibration-based EMEH produces low power from a variety of sources, making it unsuitable for micro-electronic devices unless the voltage is increased. As a result, the primary reason for employing a boost converter is to enhance the output from the input voltage in order to achieve the desired output. In comparison to the closed-loop stage, the boost's controlling efficiency is very low in the open-loop stage. The operating condition for an open-loop device is that the input and output voltages be fixed depending on the application. Therefore, the advantages of isolated converters are i. run at a low frequency, ii. storing energy in a coupled inductor per cycle, and iii. transferring to load in subsequent cycles that are suitable for EMEH applications because of low power loss, easy to implement, and low cost. Preceding research has shown that a duty cycle-controlled switch-mode DC-DC boost converter will achieve the best results in the EMEH system. Table 3 shows the comparison of various DC-DC converters topologies for EMEH. 


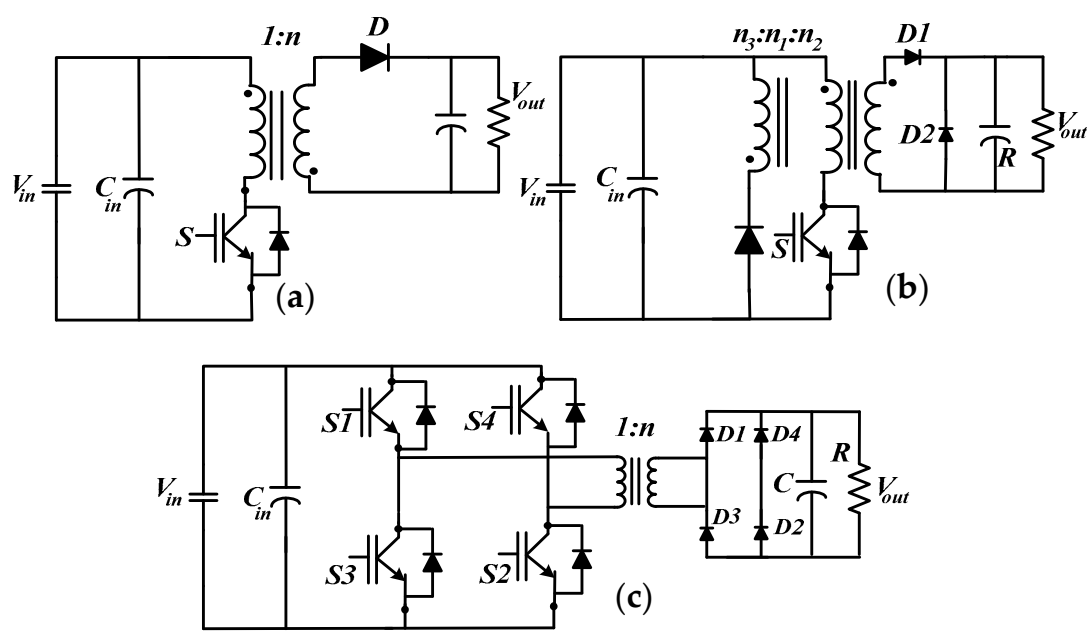

Figure 31. Isolated DC-DC converter: (a) flyback converter, (b) forward converter, and (c) full-bridge converter [134].

Table 3. Comparison of different DC-DC converters topology for energy harvesting.

\begin{tabular}{cccccccc}
\hline Refs. & Converter & $\begin{array}{c}\text { Implementation } \\
\text { Difficulty }\end{array}$ & Switch Time & Frequency & Load & Efficiency (\%) & Applications \\
\hline$[136]$ & Buck & Simple & Low & $53 \mathrm{~Hz}$ & Resistive & $59 \%$ & EH \\
\hline$[115]$ & Boost & Simple & Low & $40 \mathrm{~Hz}$ & Resistive & High & EMEH \\
\hline$[28]$ & $\begin{array}{c}\text { Buck-boost } \\
\text { converter }\end{array}$ & Complex & High & $8 \mathrm{~Hz}$ & Resistive & $41.7 \%$ & EMEH \\
\hline$[39]$ & $\begin{array}{c}\text { Flyback } \\
\text { converter }\end{array}$ & Complex & High & $50 \mathrm{~Hz}$ & Resistive & Low & EH \\
\hline$[96]$ & $\begin{array}{c}\text { Full-bridge } \\
\text { converter }\end{array}$ & Complex & Low & $30 \mathrm{kHz}$ & Resistive & $87-88 \%$ & EMEH \\
\hline
\end{tabular}

\section{Overview of Electromagnetic Energy Harvesting Techniques and Prototypes}

The EMEH research has been conducted for several decades, and it presents different ideas, functions, and utilities. Generally, the overall EMEH process is composed depending on energy source, power electronic circuit, and storage devices [75,137]. These three basic components must always be present to ensure the harvest of convenient electrical charges. The following section summarizes the common energy sources and reviews EMEH prototypes.

\subsection{Electromagnetic Energy Harvester Devices}

Electromagnetic harvesters represent an EH approach that uses a magnetic field to alter mechanical energy to electrical energy [138-140]. An AC voltage is induced by the analogous signal between the mass and the pick-up coil, according to Faraday's Law; the flux of a magnetic field varies with time. When a conductor is put in a magnetic field according to Faraday's induction law, which is often referred to as electromagnetic induction, an electromotive force is induced [141,142]. The coil moves by various amounts of magnetic flux; thus, an AC voltage is generated in the coil. When an outer mechanical force pushes an electrically conductive coil to cut the magnetic induction field between magnets, an electric charge is produced in the coil. This explains a combined principle to generate electrical energy. In [142], the authors indicated a magnetic field, which is produced by current resonant electrodes in the low power devices, which harvest electricity to run micro-device sensors. Table 4 presents the available products in the market, which are generated using the EMEH technique. 
Table 4. Market survey of magnetic field-based items for energy harvesting.

\begin{tabular}{|c|c|c|}
\hline $\begin{array}{c}\text { Product } \\
\text { (Company) }\end{array}$ & Description/Functionality & Shape \\
\hline $\begin{array}{c}\text { Power Line } \\
\text { Sensor } \\
\text { (Protura) } \\
\text { [143] }\end{array}$ & $\begin{array}{l}\text { - Sends information using } \\
\text { general packet radio service. } \\
\text { - Driven by a two-piece, specially built } \\
\text { transformer that controls from the } \\
\text { magnetic field along the transmission } \\
\text { line scavenges. } \\
\text { - Powered by a harvesting circuit when } \\
\text { the line current is more than } 55 \mathrm{~A} \text {. The } \\
\text { auxiliary supply power donut (USi) } \\
\text { powers the device when the current is } \\
\text { lower than the provided value [144]. } \\
\text { - Transmits data on demand }\end{array}$ & \\
\hline $\begin{array}{c}\text { Power } \\
\text { Donut } \\
\text { (USi) [145] }\end{array}$ & $\begin{array}{l}\text { - Transfers on-demand data through a } \\
\text { global mobile communications wireless } \\
\text { cell phone technology framework. } \\
\text { - Operates using harvested energy } \\
\text { given line currents of above } 50 \mathrm{~A} \text {. }\end{array}$ & \\
\hline $\begin{array}{l}\text { Polydimethylsiloxane } \\
\text { (PDMS) [146] }\end{array}$ & $\begin{array}{l}\text { PDMS are largely utilized } \\
\text { electronegativity polymer films in the } \\
\text { triboelectric nano-generator. The PDMS } \\
\text { dimension is } 50 \mathrm{~mm} \times 50 \mathrm{~mm} \text { and is } \\
\text { designed as a support case for soft } \\
\text { PDMS springs. }\end{array}$ & \\
\hline
\end{tabular}

\subsection{Other Related Works on Electromagnetic Energy Harvesters Devices}

The following section in Table 5 denotes various types of EMEH devices, their features, specifications, dimensions, and functionality.

Table 5. Electromagnetic energy-harvesting devices' specifications and figures.

\begin{tabular}{cc}
\hline References & Description/Functionality \\
\hline Several magnetic field designs for harvesting \\
techniques have been proposed in previous \\
studies. The power line sensor (Protura) is an \\
available item that extracts energy from \\
electromagnetic fields.
\end{tabular}

\section{Figures}

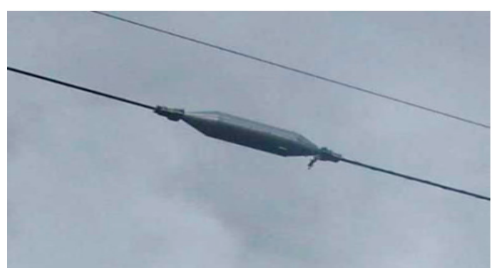

Power line sensor (Protura).

It is a hybrid power-producing method for sensors. In this system, a number of coil-grappled magnets joined to a cantilever are utilized to produce power from an electromagnetic generator. With the system, around $25.45 \mathrm{~mW}$ can be obtained with a frequency of $60 \mathrm{~Hz}$.

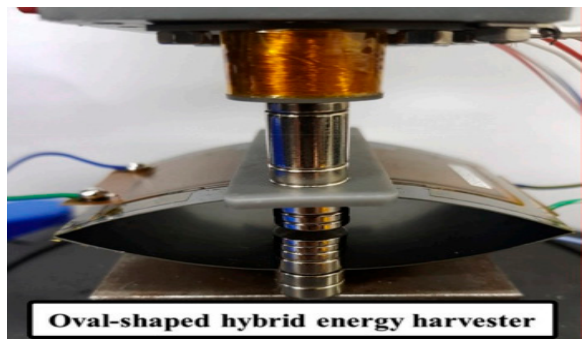

Electromagnetic hybrid energy harvester. 
Table 5. Cont.

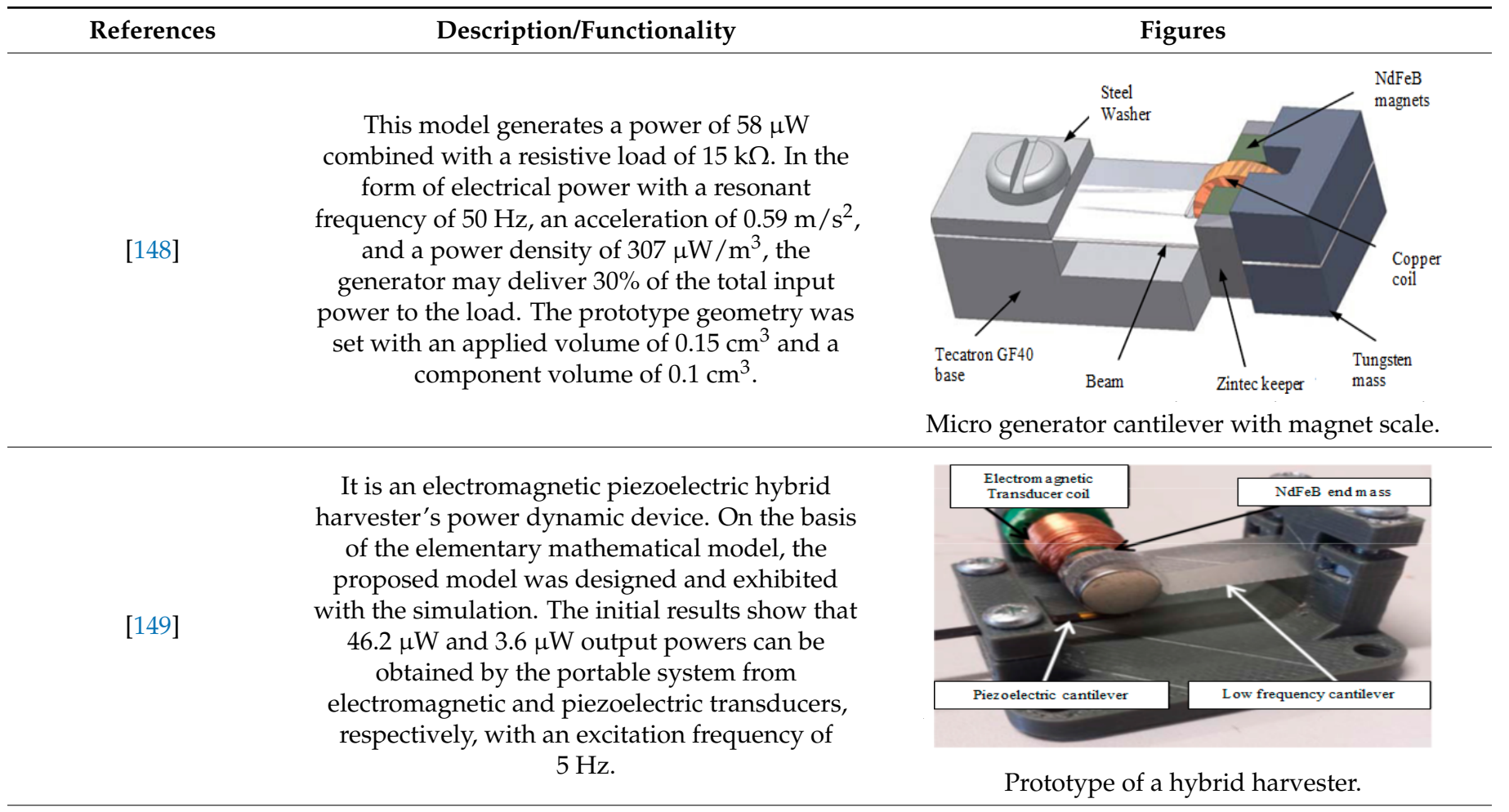

A similar axial-flux permanent magnets generator with eight poles with a diameter of $5 \mathrm{~mm}$. The coil was fabricated differently, given the four layers of copper wound around the stator. $\mathrm{NdFeB}$ magnets were utilized in the rotor.

These fabrications resulted in a total coil resistance of $30 \Omega$. When the rotor was rotated [150] using a spindle, given an air gap of $1 \mathrm{~mm}$, the generator delivered a maximum power of

$0.412 \mathrm{~mW}$ at $2.2 \mathrm{krpm}$. The authors also indicated the device later generated stator coils using low temperature co-fired ceramic materials.

With the use of this technique and with the modification of the test setup, the output power

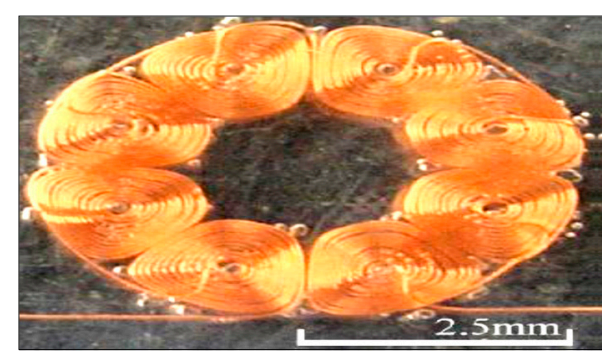

Stator with filament windings shown in one layer. levels reached $1.89 \mathrm{~mW}$ at $13,325 \mathrm{rpm}$.

A generator with four magnets, with a volume length of $1.1 \mathrm{~cm}$, a width of $0.9 \mathrm{~cm}$, and a height $0.85 \mathrm{~cm}$. The outcome of this generator is $1 \mathrm{~V}$ from an input range of $150 \mathrm{mV}$ at resonance [151] frequency $106 \mathrm{~Hz}$ with an acceleration level of $2.6 \mathrm{~m} / \mathrm{s}^{2}$. The generator attached with a car engine and from the system produces a peak power of $3.9 \mathrm{~mW}$, which can be obtained with a peak power of $157 \mu \mathrm{W}$.

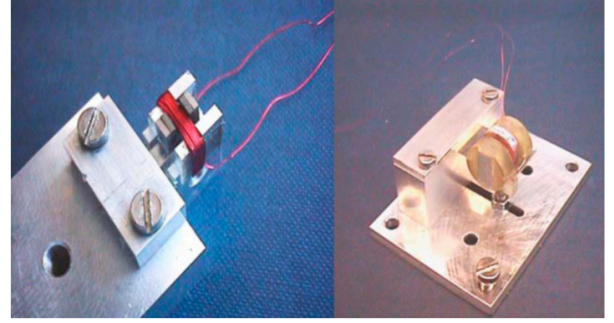

Electromagnetic generator powered by vibration. 
Table 5. Cont.

\begin{tabular}{cc}
\hline References & Description/Functionality \\
\hline & \\
& An electromagnetic generator $(\mathrm{EG})$ with discrete \\
coil fabricated with silicon materials. The \\
dimensions of the EG are 525- $\mu$ m-thick silicon \\
wafer and $25-\mu \mathrm{m}$-thick copper wire. The EG \\
produces $0.38 \mathrm{~V}$ with a frequency of $6.4 \mathrm{kHz}$.
\end{tabular}

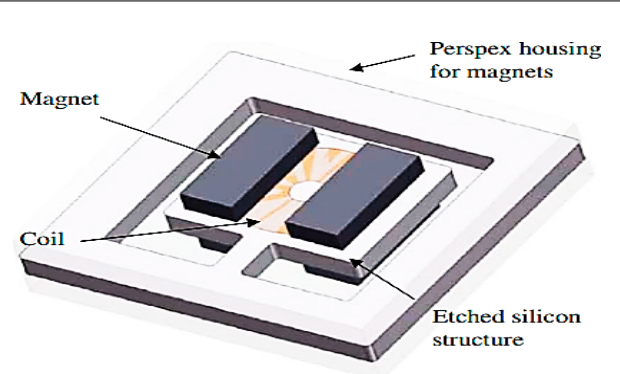

Diagram of silicon electromagnetic generator with discrete coil.

This structure contains three spring-mass systems and the proof masses are patterned with double-layer spiral-shaped aluminum coils with dimensions of $10 \mu \mathrm{m}$ in width and $1 \mu \mathrm{m}$ in depth. On the other hand, the dimensions of the MEMS

EMEH chip, $3 \mathrm{~mm}$ in diameter, and $2 \mathrm{~mm}$ in height, are mounted through a supporting beam on top of the harvester array. The downside to such a scheme is, it is complicated and costly. Therefore, proper selection of materials at low cost is the best solution to overcome this problem.

It is a meso scale vibration-based EMEH devices with double-layer spring FR4 materials. The basic principle of this vibration transducer is one side fixed and another side open free to move and generate electrical charge via pressure.

Therefore, the advantage of such devices is that they can run low-power sensors that are currently powered by the battery; such devices are suitable for the IoT applications.

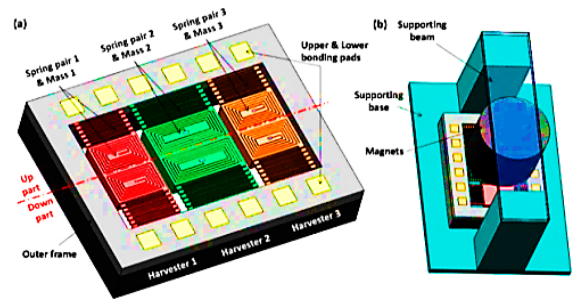

Working principle illustration of electromagnetic MEMS energy harvester (a); setup of electromagnetic MEMS energy harvester (b).

\section{$[154,155]$}

It is a nonlinear vibration-based EMEH structure. The model consists of a combination of

Polyethylene terephthalate film, magnets, copper coils, and aluminum shells. The advantage of

$[156,157]$ this model is the upper and lower copper coils are connected in series to gain a maximum voltage outcome. The restriction of this model was the production of a cost-effective combination of composite materials.

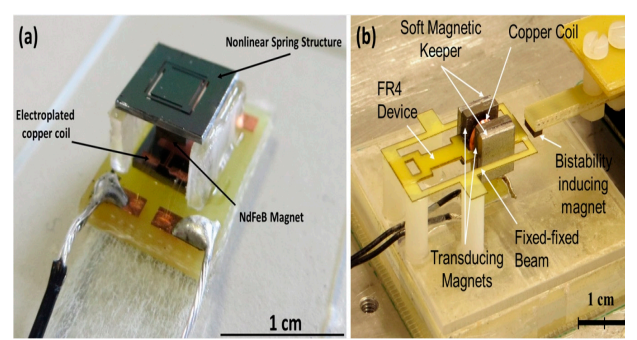

(a) Measurement setup of MEMS electromagnetic vibration energy harvester, (b) Meso-scale prototype of Electromagnetic vibration energy harvester.

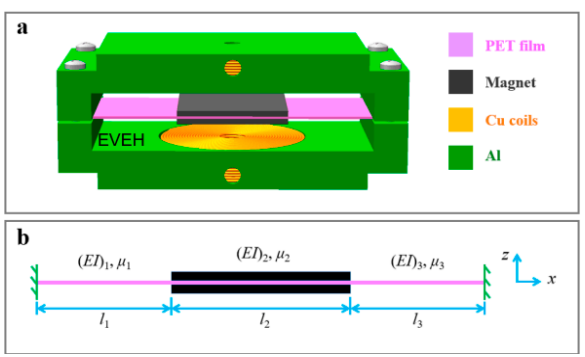

Schematic of the double-clamped beam electromagnetic vibration energy harvester. 
Table 5. Cont.

\begin{tabular}{|c|c|c|}
\hline References & Description/Functionality & Figures \\
\hline$[41]$ & $\begin{array}{l}\text { It is an EMEH device, which consists of } \\
\text { aluminum, pure iron, and copper winding in the } \\
\text { top side, and coil bobbins, copper windings, and } \\
\text { aluminum in the bottom side respectively. The } \\
\text { dimension of this model is } 3.7 \text { mm copper } \\
\text { winding pitch, which matches the width of the } \\
\text { magnet. The minimum distance between the } \\
\text { magnet array and the coil is } 0.2 \mathrm{~mm} \text {, which is the } \\
\text { aluminum housing's minimum thickness. The } \\
\text { schematic diagram and fabrication of the } \\
\text { electromagnetic energy harvester. The dimension } \\
\text { of each magnet after fabrication is } 3.18 \times 12.7 \times \\
1.59 \text { mm }{ }^{3} \text { and } 12.7 \times 12.7 \times 0.2 \text { mm }{ }^{3} \text {. The } \\
\text { restriction of this model manufacturing process, } \\
\text { however, is time consuming with low output } \\
\text { power generation. Therefore, the optimal } \\
\text { materials and the required dimensions of the } \\
\text { systems can be fine-tuned to overcome this } \\
\text { problem optimization technique. }\end{array}$ & $\begin{array}{l}\text { Electromagnetic energy harvester fabrication of the } \\
\text { (unit: mm): (a) top side; (b) bottom. }\end{array}$ \\
\hline
\end{tabular}

\section{Issues and Challenges}

The main goal of EMEH for autonomous sensors plays an important role in powering up the devices, however, it has some problems such as availability of power sources, storage, energy dissipation, large size, converter for boost up power, and cost [141,158]. Modifications are required to make less energy dissipate, small size with low cost sensors, and overall management $[159,160]$. A small amount of power for low-energy electronics is given by the EMEH system.

The power source comprises a combination of voltage and current, frequency profile, and harmonics. There are a number of issues that may arise with environmental ambient sources, such as distortion of voltage due to current harmonics, flicker, voltage sag, and voltage surge [161,162]. Moreover, because of the geometric shapes and proper material selection problem of the EMEH devices, more research is necessary to improve the efficiency power [163-165]. Many studies are focused on increasing the efficiency of EMEH systems to improve power electronic circuits such as the converter, inverter, and controller $[96,110,111,113]$.

Generally, standalone micro EMEH systems are useful in areas where electricity is not available, especially in remote areas. There are so many methods and materials, for example, photovoltaic, thermoelectric, piezoelectric, radio frequency, electrostatic, and capacitive, which can be used for micro EMEH systems $[39,144,166]$. Many methods have been developed to extract energy from the different resources available, such as wind, vibration, solar, chemical, thermal, wave, radiofrequency, biological, etc. [15,57,95]. However, it has some issues such as generating low power, instability, fluctuation, harmonics, and it is costly. Further researches are required to create stable, controlled, low-cost maintenance, and long-term sustainability.

Currently, WSNs and the IoT are getting more and more attention for low-power EMEH devices $[54,167]$. WSNs and IoT are the favorites in industrial, remote areas as well as in commercial applications, because it has modern and fast communication processors as well as low power usage $[26,55,168]$. This network can be used in a poor and harsh environment where the wired system is not possible. IoT is a physical network that assigns IP addresses to devices in the network for internet connectivity, and the output information of these devices can be sent to any place in the world. The drawback of the WSNs application, however, is that is far from the power line and those devices powered 
by the battery currently. However, the battery life is limited, it must be recharged regularly, and the cost of replacing the battery is typically high.

\section{Conclusions and Recommendations}

This paper presented a comprehensive review of EMEH systems for ATS, giving a special focus on recent technological developments and existing barriers. There are various applications based on EMEH, such as WSNs, wireless building automation, battery-less networks, low-power switches, automotive, low power electronics devices, IoT, consumer electronics, and bio-medical that are presented in this study. It is necessary to achieve the ultimate purpose of avoiding replacing batteries or providing ATS with free perpetual energy. In this system, batteries are not used, thereby reducing the expenditure for buying batteries and the labor cost required for battery replacement. The batteries are used to power the nodes of the sensors but having a limited life, which restricts the performance and application of WSNs. To overcome these problems and to make the sensors selfpowered, the best option is harvesting energy from the ambient energy resources. Finally, harvesting energy from ambient energy resources offers several advantages, including the supply of potential energy to common low-power devices such as motion sensors.

Many past research works are summarized along with the numerous approaches that are acceptable for the research based on the literature survey. The review helps in realizing the basics of geometrical dimensional outcomes, parameter values, and scalability to model EMEH devices, which is suitable for low power electronic devices. The phenomenon of devices, such as the low power harvesting interface circuit methods, converter, and controller technique, is also presented in this review. Furthermore, this review indicates the numerous types of power electronic topologies for the betterment of EMEH. The study outlines a comprehensive survey of power electronic circuits, converters, controllers, and identified implementation in low-power applications to associate their significant contribution in the improvement. The conduction and switching losses of an AC-DC converter are minimal, but the power factor and harmonic distortion are high. A DC-DC converter has a fast response time and high performance, but it suffers from high switching loss. Finally, various methods are suggested in this study to overcome the limitations of the controller, converter, and low-power electronics devices for EMEH application.

There are some recommendations for the improvement of the EMEH system. A power electronic circuit and converter, inverter, and controller have been reported in this review, such as:

- More studies should be carried to improve energy density, power efficiency, and low resonance frequency for EMEH deceives.

- A switching device with the PWM technique can control the power in AC-DC converters but reduces the power factor and adds harmonics, which can be avoided by a low pass filter and PWM switch. Whereas, in a DC-DC converter for power factor improvement, a power factor correction capacitor is a good option.

- With regards to gaining accurate system performance and market acceptance, security, flexibility, long life, and stability problems of the EH transducer need to be addressed.

- Optimization techniques can be utilized to get the optimal parameter geometry shape of the EMEH devices such as length, width, and thickness.

- An intelligent real-time interface controller board can be performed to implement the EMEH circuit prototype for the robust, smart, and efficient converter, controller, and inverter.

- It is important to address a capable energy storage scheme such as supercapacitor charging/discharging, protection, reliability, scale, expense, life cycle, and overall management.

- Further research on the power, safety, control interface, energy management, and features of an advanced EMEH device are needed to improve the efficiency of energy storage in EH applications. 
Author Contributions: Conceptualization, methodology, original draft writing, visualization, editing and funding acquisition. M.R.S., M.H.M.S.; J.L.O.; and J.V. contributed by writing of sections, reviewing, visualization and editing. All authors have read and agreed to the published version of the manuscript.

Funding: Universidad Antonio de Nebrija for funding under Grant Code the Comunidad de Madrid [grant SEGVAUTO 4.0-CM-P2018EEMT-4362] and the Agencia Estatal de Investigación [grant RETOS 2018-RTI2018-095923-B-C22].

Conflicts of Interest: The authors declare no conflict of interest.

\section{References}

1. Bo, L.D.; Gardonio, P.; Turco, E. Analysis and scaling study of vibration energy harvesting with reactive electromagnetic and piezoelectric transducers. J. Sound Vib. 2020, 484, 115510. [CrossRef]

2. Kim, J. A Study on the Analytic Power Estimation of the Electromagnetic Resonant Energy Harvester for the High-Speed Train. Electronics 2020, 9, 403. [CrossRef]

3. Wu, Z.; Tang, J.; Zhang, X.; Yu, Z. An energy harvesting bracelet. Appl. Phys. Lett. 2017, 111, 013903. [CrossRef]

4. Sarker, M.R.; Julai, S.; Sabri, M.F.M.; Said, S.M.; Islam, M.; Tahir, M. Review of piezoelectric energy harvesting system and application of optimization techniques to enhance the performance of the harvesting system. Sens. Actuators A Phys. 2019, 300, 111634. [CrossRef]

5. Moghe, R.; Yang, Y.; Lambert, F.; Divan, D. A scoping study of electric and magnetic field energy harvesting for wireless sensor networks in power system applications. In Proceedings of the 2009 IEEE Energy Conversion Congress and Exposition, San Jose, CA, USA, 20-24 September 2009; pp. 3550-3557.

6. Grossi, M. Energy Harvesting Strategies for Wireless Sensor Networks and Mobile Devices: A Review. Electronics 2021, 10, 661. [CrossRef]

7. Jiao, D.; Ke, L.; Liu, S.; Chan, F.T. Optimal Energy-Delay in Energy Harvesting Wireless Sensor Networks with Interference Channels. Sensors 2019, 19, 785. [CrossRef] [PubMed]

8. Wang, H.; Li, W.; Xu, D.; Kan, J. A Hybrid Microenergy Storage System for Power Supply of Forest Wireless Sensor Nodes. Electronics 2019, 8, 1409. [CrossRef]

9. Li, Y.; Hamed, E.A.; Zhang, X.; Luna, D.; Lin, J.-S.; Liang, X.; Lee, I. Feasibility of Harvesting Solar Energy for Self-Powered Environmental Wireless Sensor Nodes. Electronics 2020, 9, 2058. [CrossRef]

10. Sarker, M.R.; Mohamed, R.; Saad, M.H.M.; Tahir, M.; Hussain, A.; Mohamed, A. A Hybrid Optimization Approach for the Enhancement of Efficiency of a Piezoelectric Energy Harvesting System. Electronics 2021, 10, 75. [CrossRef]

11. Banerjee, S.; Bairagi, S.; Ali, S.W. A critical review on lead-free hybrid materials for next generation piezoelectric energy harvesting and conversion. Ceram. Int. 2021, 47, 16402-16421. [CrossRef]

12. Wang, Z.L.; Song, J. Piezoelectric nanogenerators based on zinc oxide nanowire arrays. Science 2006, 312, 242-246. [CrossRef]

13. Zhao, L.; Duan, J.; Liu, L.; Wang, J.; Duan, Y.; Vaillant-Roca, L.; Yang, X.; Tang, Q. Boosting power conversion efficiency by hybrid triboelectric nanogenerator/silicon tandem solar cell toward rain energy harvesting. Nano Energy 2021, 82, 105773. [CrossRef]

14. Shakeel, M.; Rehman, K.; Ahmad, S.; Amin, M.; Iqbal, N.; Khan, A. A low-cost printed organic thermoelectric generator for low-temperature energy harvesting. Renew. Energy 2020, 167, 853-860. [CrossRef]

15. Li, X.; Li, Z.; Bi, C.; Liu, B.; Su, Y. Study on Wind Energy Harvesting Effect of a Vehicle-Mounted Piezo-Electromagnetic Hybrid Energy Harvester. IEEE Access 2020, 8, 167631-167646. [CrossRef]

16. Ghany, A.; Shehata, E.; Elsayed, A.-H.; Mohamed, Y.; Alhelou, H.H.; Siano, P.; Diab, A. Novel Switching Frequency FCS-MPC of PMSG for Grid-Connected Wind Energy Conversion System with Coordinated Low Voltage Ride Through. Electronics 2021, 10, 492. [CrossRef]

17. Bakytbekov, A.; Nguyen, T.Q.; Li, W.; Cottrill, A.L.; Zhang, G.; Strano, M.S.; Salama, K.N.; Shamim, A. Multi-source ambient energy harvester based on RF and thermal energy: Design, testing, and IoT application. Energy Sci. Eng. 2020, 8, 3883-3897. [CrossRef]

18. Gholikhani, M.; Shirazi, S.Y.B.; Mabrouk, G.M.; Dessouky, S. Dual electromagnetic energy harvesting technology for sustainable transportation systems. Energy Convers. Manag. 2021, 230, 113804. [CrossRef]

19. Falk, M.; Shleev, S. Hybrid dual-functioning electrodes for combined ambient energy harvesting and charge storage: Towards self-powered systems. Biosens. Bioelectron. 2019, 126, 275-291. [CrossRef]

20. Tang, X.; Wang, X.; Cattley, R.; Gu, F.; Ball, A.D. Energy Harvesting Technologies for Achieving Self-Powered Wireless Sensor Networks in Machine Condition Monitoring: A Review. Sensors 2018, 18, 4113. [CrossRef] [PubMed]

21. Chamanian, S.; Uluşan, H.; Zorlu, Ö.; Baghaee, S.; Uysal-Biyikoglu, E.; Külah, H. Wearable battery-less wireless sensor network with electromagnetic energy harvesting system. Sens. Actuators A Phys. 2016, 249, 77-84. [CrossRef]

22. Hu, Z.; Liu, Q.; Chou, S.-L.; Dou, S.-X. Two-Dimensional Material-Based Heterostructures for Rechargeable Batteries. Cell Rep. Phys. Sci. 2021, 2, 100286. [CrossRef]

23. Li, Z.; Luo, J.; Xie, S.; Xin, L.; Guo, H.; Pu, H.; Yin, P.; Xu, Z.; Zhang, D.; Peng, Y.; et al. Instantaneous peak 2.1 W-level hybrid energy harvesting from human motions for self-charging battery-powered electronics. Nano Energy 2021, 81, 105629. [CrossRef] 
24. Ma, J.; Shang, P.; Zou, X.; Ma, N.; Ding, Y.; Sun, J.; Cheng, Y.; Tao, L.; Lu, C.; Su, Y.; et al. A hybrid transfer learning scheme for remaining useful life prediction and cycle life test optimization of different formulation Li-ion power batteries. Appl. Energy 2021, 282, 116167. [CrossRef]

25. Alghisi, D.; Ferrari, V.; Crescini, D.; Touati, F.; Ben Mnaouer, A.B. Single- and multi-source battery-less power management circuits for piezoelectric energy harvesting systems. Sens. Actuators A Phys. 2017, 264, 234-246. [CrossRef]

26. Sherazi, H.H.R.; Grieco, L.A.; Boggia, G. A comprehensive review on energy harvesting MAC protocols in WSNs: Challenges and tradeoffs. Ad Hoc Netw. 2018, 71, 117-134. [CrossRef]

27. Antonopoulos, C.P.; Voros, N.S. Resource efficient data compression algorithms for demanding, WSN based biomedical applications. J. Biomed. Inform. 2016, 59, 1-14. [CrossRef]

28. Li, K.; He, X.; Wang, X.; Jiang, S. A Nonlinear Electromagnetic Energy Harvesting System for Self-Powered Wireless Sensor Nodes. J. Sens. Actuator Netw. 2019, 8, 18. [CrossRef]

29. Izhar; Khan, F.U. Electromagnetic based acoustic energy harvester for low power wireless autonomous sensor applications. Sens. Rev. 2018, 38, 298-310. [CrossRef]

30. Kubba, A.E.; Jiang, K. A Comprehensive Study on Technologies of Tyre Monitoring Systems and Possible Energy Solutions. Sensors 2014, 14, 10306-10345. [CrossRef] [PubMed]

31. Amirtharajah, R.; Chandrakasan, A. Self-powered signal processing using vibration-based power generation. IEEE J. Solid-State Circuits 1998, 33, 687-695. [CrossRef]

32. Xu, Y.; Ha, D.S.; Xu, M. Energy harvesting circuit with input matching in boundary conduction mode for electromagnetic generators. In Proceedings of the 2017 IEEE International Symposium on Circuits and Systems (ISCAS), Baltimore, MD, USA, 28-31 May 2017; pp. 1-4.

33. Gu, Y.; Liu, W.; Zhao, C.; Wang, P. A goblet-like non-linear electromagnetic generator for planar multi-directional vibration energy harvesting. Appl. Energy 2020, 266, 114846. [CrossRef]

34. Kakou, P.; Barry, O. Simultaneous vibration reduction and energy harvesting of a nonlinear oscillator using a nonlinear electromagnetic vibration absorber-inerter. Mech. Syst. Signal. Process. 2021, 156, 107607. [CrossRef]

35. Rahman, M.T.; Rana, S.S.; Salauddin, M.; Maharjan, P.; Bhatta, T.; Kim, H.; Cho, H.; Park, J.Y. A highly miniaturized freestanding kinetic-impact-based non-resonant hybridized electromagnetic-triboelectric nanogenerator for human induced vibrations harvesting. Appl. Energy 2020, 279, 115799. [CrossRef]

36. He, J.; Fan, X.; Mu, J.; Wang, C.; Qian, J.; Li, X.; Hou, X.; Geng, W.; Wang, X.; Chou, X. 3D full-space triboelectric-electromagnetic hybrid nanogenerator for high-efficient mechanical energy harvesting in vibration system. Energy 2020, 194, 116871. [CrossRef]

37. Li, Z.; Liu, Y.; Yin, P.; Peng, Y.; Luo, J.; Xie, S.; Pu, H. Constituting abrupt magnetic flux density change for power density improvement in electromagnetic energy harvesting. Int. J. Mech. Sci. 2021, 198, 106363. [CrossRef]

38. Chen, J.; Peng, H.; Feng, Z.; Chen, Y.; Zeng, C.; Kang, Y. A Fully PCB Integrated Self-Powered Micro Generator for Vibration Electromagnetic Harvesting. In Proceedings of the 2020 IEEE Applied Power Electronics Conference Exposition (APEC), New Orleans, LA, USA, 15-19 March 2020; pp. 3594-3599.

39. Siddique, A.R.M.; Mahmud, S.; Heyst, B.v. A comprehensive review on vibration based micro power generators using electromagnetic and piezoelectric transducer mechanisms. Energy Convers. Manag. 2015, 106, 728-747. [CrossRef]

40. Iqbal, M.; Khan, F.U.; Mehdi, M.; Cheok, Q.; Abas, E.; Nauman, M.M. Power harvesting footwear based on piezo-electromagnetic hybrid generator for sustainable wearable microelectronics. J. King Saud Univ. Eng. Sci. 2020. [CrossRef]

41. Chae, S.H.; Ju, S.; Choi, Y.; Chi, Y.-E.; Ji, C.-H. Electromagnetic Linear Vibration Energy Harvester Using Sliding Permanent Magnet Array and Ferrofluid as a Lubricant. Micromachines 2017, 8, 288. [CrossRef] [PubMed]

42. Cho, S.J.; Kim, J.H. Linear electromagnetic electric generator for harvesting vibration energy at frequencies more than $50 \mathrm{~Hz}$. Adv. Mech. Eng. 2017, 9, 168781401771900. [CrossRef]

43. Yan, B.; Wang, Z.; Ma, H.; Bao, H.; Wang, K.; Wu, C. A novel lever-type vibration isolator with eddy current damping. J. Sound Vib. 2021, 494, 115862. [CrossRef]

44. Parekh, M.; Magnusson, J.; Engdahl, G. Study of an Electromagnetic Damping Actuator-VDE Conference Publication. In Proceedings of the ACTUATOR 2018; 16th International Conference on New Actuators, Bremen, Germany, 25-27 June 2018.

45. Li, S.; Xu, J.; Pu, X.; Tao, T.; Gao, H.; Mei, X. Energy-harvesting variable/constant damping suspension system with motor based electromagnetic damper. Energy 2019, 189, 116199. [CrossRef]

46. Pan, Q.; He, T.; Xiao, D.; Liu, X. Design and Damping Analysis of a New Eddy Current Damper for Aerospace Applications. Lat. Am. J. Solids Struct. 2016, 13, 1997-2011. [CrossRef]

47. Pei, Y.; Liu, Y.; Zuo, L. Multi-resonant electromagnetic shunt in base isolation for vibration damping and energy harvesting. J. Sound Vib. 2018, 423, 1-17. [CrossRef]

48. Kiziroglou, M.; Wright, S.; Yeatman, E. Coil and core design for inductive energy receivers. Sens. Actuators A Phys. 2020, 313, 112206. [CrossRef]

49. Han, Q.; Ding, Z.; Sun, W.; Xu, X.; Chu, F. Hybrid triboelectric-electromagnetic generator for self-powered wind speed and direction detection. Sustain. Energy Technol. Assess. 2020, 39, 100717. [CrossRef]

50. Yen, K.T. Energy Harvesting Autonomous Sensor Systems: Design, Analysis, and Practical Implementation; CRC Press: Boca Raton, FL, USA, 2013; ISBN 9781138074095. 
51. Penella-López, M.T.; Gasulla-Forner, M.; Penella-López, M.T.; Gasulla-Forner, M. Powering Autonomous Sensors; Springer: Dordrecht, The Netherlands, 2011; pp. 1-7.

52. Kalaivaani, P.; Krishnamoorthi, R. Design and implementation of low power bio signal sensors for wireless body sensing network applications. Microprocess. Microsyst. 2020, 79, 103271. [CrossRef]

53. Mahmood, M.F.; Mohammed, S.L.; Gharghan, S.K.; Al-Naji, A.; Chahl, J. Hybrid Coils-Based Wireless Power Transfer for Intelligent Sensors. Sensors 2020, 20, 2549. [CrossRef]

54. Landaluce, H.; Arjona, L.; Perallos, A.; Falcone, F.; Angulo, I.; Muralter, F. A Review of IoT Sensing Applications and Challenges Using RFID and Wireless Sensor Networks. Sensors 2020, 20, 2495. [CrossRef]

55. Sunny, A.I.; Zhao, A.; Li, L.; Kanteh Sakiliba, S.K. Low-Cost IoT-Based Sensor System: A Case Study on Harsh Environmental Monitoring. Sensors 2020, 21, 214. [CrossRef]

56. DeLuca, M.; Köck, A. Current Perspectives for Autonomous Sensor Nodes. Proceedings 2020, 56, 7. [CrossRef]

57. Tholl, M.; Akarçay, H.; Tanner, H.; Niederhauser, T.; Zurbuchen, A.; Frenz, M.; Haeberlin, A. Subdermal solar energy harvestingA new way to power autonomous electric implants. Appl. Energy 2020, 269, 114948. [CrossRef]

58. Szarka, G.D.; Stark, B.H.; Burrow, S.G. Review of Power Conditioning for Kinetic Energy Harvesting Systems. IEEE Trans. Power Electron. 2011, 27, 803-815. [CrossRef]

59. Wu, Z.; Cheng, T.; Wang, Z.L. Self-Powered Sensors and Systems Based on Nanogenerators. Sensors 2020, 20, 2925. [CrossRef] [PubMed]

60. Wang, Z.L. Energy harvesting for self-powered nanosystems. Nano Res. 2008, 1, 1-8. [CrossRef]

61. Wu, Z.; Wen, Y.; Li, P. A Power Supply of Self-Powered Online Monitoring Systems for Power Cords. IEEE Trans. Energy Convers. 2013, 28, 921-928. [CrossRef]

62. Khan, S.A.; Rajkumar, R.K.; Wan, W.Y.; Syed, A. Supercapacitor-Based Hybrid Energy Harvesting for Low-Voltage System. In Supercapacitors-Theoretical and Practical Solutions; IntechOpen: London, UK, 2018.

63. Yin, J.; Wen, Z.; Yu, J.; Shi, X.; Wang, G.; Yang, Y.-E.; Man, J.; Sun, J.; Cui, L. Self-templated hierarchical TiO2@C microrods with synergic battery/capacitor hybrid energy storage: Toward ultra-long cycling life and outstanding rate performance. J. Alloys Compd. 2019, 808, 151728. [CrossRef]

64. Chan, K.-Y.; Pham, D.Q.; Demir, B.; Yang, D.; Mayes, E.L.; Mouritz, A.P.; Ang, A.S.; Fox, B.; Lin, H.; Jia, B.; et al. Graphene oxide thin film structural dielectric capacitors for aviation static electricity harvesting and storage. Compos. Part B Eng. 2020, 201, 108375. [CrossRef]

65. Deka, B.K.; Hazarika, A.; Lee, S.; Kim, D.Y.; Park, Y.-B.; Park, H.W. Triboelectric-nanogenerator-integrated structural supercapacitor based on highly active P-doped branched $\mathrm{Cu}-\mathrm{Mn}$ selenide nanowires for efficient energy harvesting and storage. Nano Energy 2020, 73, 104754. [CrossRef]

66. Zhang, X.; Zhang, Z.; Pan, H.; Salman, W.; Yuan, Y.; Liu, Y. A portable high-efficiency electromagnetic energy harvesting system using supercapacitors for renewable energy applications in railroads. Energy Convers. Manag. 2016, 118, 287-294. [CrossRef]

67. Bai, Y.; Muralidharan, N.; Sun, Y.-K.; Passerini, S.; Whittingham, M.S.; Belharouak, I. Energy and environmental aspects in recycling lithium-ion batteries: Concept of Battery Identity Global Passport. Mater. Today 2020, 41, 304-315. [CrossRef]

68. Ahmed, F.; Kervadec, C.; Le Moullec, Y.; Tamberg, G.; Annus, P. Autonomous Wireless Sensor Networks: Implementation of Transient Computing and Energy Prediction for Improved Node Performance and Link Quality. Comput. J. 2018, 62, 820-837. [CrossRef]

69. Nikolov, D.N.; Ganev, B.T.; Rusev, R.P. Energy harvesting power supply for an autonomous environmental sensor node. In Proceedings of the 2019 IEEE XXVIII International Scientific Conference Electronics (ET), Sozopol, Bulgaria, 12-14 September 2019; pp. 1-4.

70. Jung, I.; Choi, J.; Park, H.-J.; Lee, T.-G.; Nahm, S.; Song, H.-C.; Kim, S.; Kang, C.-Y. Design principles for coupled piezoelectric and electromagnetic hybrid energy harvesters for autonomous sensor systems. Nano Energy 2020, 75, 104921. [CrossRef]

71. Xu, Y.; Bader, S.; Magno, M.; Mayer, P.; Oelmann, B. Energy-autonomous On-rotor RPM Sensor Using Variable Reluctance Energy Harvesting. In Proceedings of the 2019 IEEE 8th International Workshop on Advances in Sensors and Interfaces (IWASI), Otranto, Italy, 13-14 June 2019; pp. 175-180.

72. Fernando, A.S. Energy Harvesting for Autonomous Systems; IEEE: Piscataway, NJ, USA, 2012.

73. Vu, H.S.; Nguyen, N.; Ha-Van, N.; Seo, C.; Le, M.T. Multiband Ambient RF Energy Harvesting for Autonomous IoT Devices. IEEE Microw. Wirel. Compon. Lett. 2020, 30, 1189-1192. [CrossRef]

74. Saraereh, O.A.; Alsaraira, A.; Khan, I.; Choi, B.J. A Hybrid Energy Harvesting Design for On-Body Internet-of-Things (IoT) Networks. Sensors 2020, 20, 407. [CrossRef]

75. Prauzek, M.; Konecny, J.; Borova, M.; Janosova, K.; Hlavica, J.; Musilek, P. Energy Harvesting Sources, Storage Devices and System Topologies for Environmental Wireless Sensor Networks: A Review. Sensors 2018, 18, 2446. [CrossRef] [PubMed]

76. Liu, H.; Fu, H.; Sun, L.; Lee, C.; Yeatman, E.M. Hybrid energy harvesting technology: From materials, structural design, system integration to applications. Renew. Sustain. Energy Rev. 2021, 137, 110473. [CrossRef]

77. Yang, F.; Du, L.; Chen, W.; Li, J.; Wang, Y.; Wang, D. Hybrid energy harvesting for condition monitoring sensors in power grids. Energy 2017, 118, 435-445. [CrossRef]

78. Lau, D.; Song, N.; Hall, C.; Jiang, Y.; Lim, S.; Perez-Wurfl, I.; Ouyang, Z.; Lennon, A. Hybrid solar energy harvesting and storage devices: The promises and challenges. Mater. Today Energy 2019, 13, 22-44. [CrossRef] 
79. Zhu, M.; Lou, M.; Yu, J.; Li, Z.; Ding, B. Energy autonomous hybrid electronic skin with multi-modal sensing capabilities. Nano Energy 2020, 78, 105208. [CrossRef]

80. Etim, N.-B.B.; Giaouris, D.; Papadopoulos, A.I.; Patsios, H.; Papadopoulou, S.; Voutetakis, S.; Seferlis, P.; Walker, S.; Taylor, P.; Gadoue, S. Adaptive Power Pinch Analysis for Energy management of Hybrid Energy Storage Systems. In Proceedings of the 2018 IEEE International Symposium on Circuits and Systems (ISCAS), Florence, Italy, 27-30 May 2018; pp. 1-5.

81. Francesco, O. Disadvantages and Advantages of Energy Harvesting; Technical Articles; All About Circuits: Boise, ID, USA, 2019.

82. Chamanian, S.; Ciftci, B.; Ulusan, H.; Muhtaroglu, A.; Kulah, H. Power-Efficient Hybrid Energy Harvesting System for Harnessing Ambient Vibrations. IEEE Trans. Circuits Syst. I Regul. Pap. 2019, 66, 2784-2793. [CrossRef]

83. Ramírez, J.; Gatti, C.; Machado, S.; Febbo, M. Energy harvesting for autonomous thermal sensing using a linked E-shape multi-beam piezoelectric device in a low frequency rotational motion. Mech. Syst. Signal. Process. 2019, 133, 106267. [CrossRef]

84. Zhang, X.; Grajal, J.; López-Vallejo, M.; McVay, E.; Palacios, T. Opportunities and Challenges of Ambient Radio-Frequency Energy Harvesting. Joule 2020, 4, 1148-1152. [CrossRef]

85. Martins, G.C.; Mansano, A.L.; Stoopman, M.; Serdijn, W.A. Introduction to RF energy harvesting. In Wearable Sensors; Elsevier: Amsterdam, The Netherlands, 2021; pp. 311-336.

86. Mouapi, A.; Hakem, N.; Delisle, G.Y. A new approach to design of RF energy harvesting system to enslave wireless sensor networks. ICT Express 2018, 4, 228-233. [CrossRef]

87. Tan, G.P.; Bautista, J.J.P. Utilization of low cost RF harvester circuit in harnessing electrical energy from multiband RF signals. In Proceedings of the 2017 Asian Conference on Energy, Power and Transportation Electrification (ACEPT), Singapore, 24-26 October 2017; pp. 1-5.

88. Li, J.; Xiong, K.; Cao, J.; Yang, X.; Liu, T. Energy Efficiency in RF Energy Harvesting-Powered Distributed Antenna Systems for the Internet of Things. Sensors 2020, 20, 4631. [CrossRef] [PubMed]

89. Sarker, M.R.; Mohamed, R.; Saad, M.H.M.; Mohamed, A. dSPACE Controller-Based Enhanced Piezoelectric Energy Harvesting System Using PI-Lightning Search Algorithm. IEEE Access 2018, 7, 3610-3626. [CrossRef]

90. Banguero, E.; Correcher, A.; Pérez-Navarro, Á.; Morant, F.; Aristizabal, A. A Review on Battery Charging and Discharging Control Strategies: Application to Renewable Energy Systems. Energies 2018, 11, 1021. [CrossRef]

91. Gindullina, E.; Badia, L. Towards self-control of service rate for battery management in energy harvesting devices. In Proceedings of the 2017 IEEE International Conference on Communications Workshops (ICC Workshops), Paris, France, 21-25 May 2017; pp. 355-360.

92. Walton, M.; Woods, J.; Zheng, G. Efficient charging for batteryless solutions in energy harvesting. In Proceedings of the 2019 11th Computer Science and Electronic Engineering (CEEC), Colchester, UK, 18-19 September 2019; pp. 7-11.

93. Pozo, B.; Garate, J.I.; Araujo, J.A.; Ferreiro, S. Energy Harvesting Technologies and Equivalent Electronic Structural ModelsReview. Electronics 2019, 8, 486. [CrossRef]

94. Yang, F.; Du, L.; Yu, H.; Huang, P. Magnetic and Electric Energy Harvesting Technologies in Power Grids: A Review. Sensors 2020, 20, 1496. [CrossRef]

95. Shen, Y.; Lu, K. Scavenging power from ultra-low frequency and large amplitude vibration source through a new non-resonant electromagnetic energy harvester. Energy Convers. Manag. 2020, 222, 113233. [CrossRef]

96. Bolt, R.; Magno, M.; Burger, T.; Romani, A.; Benini, L. Kinetic AC/DC Converter for Electromagnetic Energy Harvesting in Autonomous Wearable Devices. IEEE Trans. Circuits Syst. II Express Briefs 2017, 64, 1422-1426. [CrossRef]

97. Yekta, H.B.; Fakhari, V. Nonlinear modeling, design and parametric study of an effective harvester in large amplitude vibration using magnetoelectric transducer. J. Magn. Magn. Mater. 2021, 519, 167419. [CrossRef]

98. Liu, K.; Chen, M.; Gong, Y.; Fan, S.; Wang, G. A $100 \mu$ W AC-DC Boost Converter for Electromagnetic Energy Harvesting with 0.2 V Peak Self-starting Voltage and 85\% Efficiency. In Proceedings of the 2018 IEEE Asia Pacific Conference on Circuits and Systems (APCCAS), Chengdu, China, 26-30 October 2019; pp. 493-496.

99. Bo, L.D.; Gardonio, P. Energy harvesting with electromagnetic and piezoelectric seismic transducers: Unified theory and experimental validation. J. Sound Vib. 2018, 433, 385-424. [CrossRef]

100. Lallart, M.; Lombardi, G. Synchronized Switch Harvesting on ElectroMagnetic System: A nonlinear technique for hybrid energy harvesting based on active inductance. Energy Convers. Manag. 2020, 203, 112135. [CrossRef]

101. Loong, C.N.; Chang, C.-C.; Dimitrakopoulos, E.G. Circuit nonlinearity effect on the performance of an electromagnetic energy harvester-structure system. Eng. Struct. 2018, 173, 449-459. [CrossRef]

102. Ma, H.; Yan, B. Nonlinear damping and mass effects of electromagnetic shunt damping for enhanced nonlinear vibration isolation. Mech. Syst. Signal. Process. 2021, 146, 107010. [CrossRef]

103. Moon, J.; Leeb, S.B. Power Electronic Circuits for Magnetic Energy Harvesters. IEEE Trans. Power Electron. 2015, 31, $270-279$. [CrossRef]

104. Asai, T.; Araki, Y.; Ikago, K. Energy harvesting potential of tuned inertial mass electromagnetic transducers. Mech. Syst. Signal. Process. 2017, 84, 659-672. [CrossRef]

105. Filho, M.J.; De Vasconcellos, R.M.G.; Ferreira, A.A. Design and Optimization of Electromagnetic Transducer for Aeroelastic Energy Harvesting. In Proceedings of the 2019 4th International Symposium on Instrumentation Systems, Circuits and Transducers (INSCIT), Sao Paulo, Brazil, 26-30 August 2019; pp. 1-5. 
106. Cai, Q.; Zhu, S. Unified strategy for overall impedance optimization in vibration-based electromagnetic energy harvesters. Int. J. Mech. Sci. 2020, 165, 105198. [CrossRef]

107. Wang, J.; Dancy, A.J.; Ha, D.S. Vibration Energy Harvesting Circuit with Impedance Matching and Wake-up for Freight Railcars. In Proceedings of the IECON 2018-44th Annual Conference of the IEEE Industrial Electronics Society, Washington, DC, USA, 21-23 October 2018; pp. 1975-1979.

108. Dancy, A.J.; Li, J.; Ha, D.S. Split-Capacitor Boost Converter Operating in Boundary Conduction Mode with Impedance Matching for Kinetic Energy Harvesting. In Proceedings of the 2020 IEEE 63rd International Midwest Symposium on Circuits and Systems (MWSCAS), Springfield, MA, USA, 9-12 August 2020; pp. 203-207.

109. Chen, J.; Peng, H.; Feng, Z.; Kang, Y. A GaN BCM AC-DC Converter for Sub-1V Electromagnetic Energy Harvesting with Enhanced Output Power. IEEE Trans. Power Electron. 2021, 1. [CrossRef]

110. Tehrani, S.Z.; Ranjbar, H.; Vial, P.; Premaratne, P. A New Efficient Power Management Interface for Hybrid ElectromagneticPiezoelectric Energy Harvesting System. In 16th International Conference on Information; Springer: Cham, Switzerland, 2019; Volume 800, pp. 537-542.

111. Balato, M.; Costanzo, L.; Vitelli, M. Resonant electromagnetic vibration harvesters: Determination of the equivalent electric circuit parameters and simplified closed-form analysis for the identification of the optimal diode bridge rectifier DC load. Int. J. Electr. Power Energy Syst. 2017, 84, 111-123. [CrossRef]

112. Rodriguez, J.C.; Nico, V.; Punch, J. A Vibration Energy Harvester and Power Management Solution for Battery-Free Operation of Wireless Sensor Nodes. Sensors 2019, 19, 3776. [CrossRef]

113. Pahlavandust, M.; Yazdani, M.R. Single-switch boost DC-DC converter with zero-current-switching, high power density and low electromagnetic interference. AEU Int. J. Electron. Commun. 2020, 121, 153229. [CrossRef]

114. Paul, S.; Lee, D.; Kim, K.; Chang, J. Nonlinear modeling and performance testing of high-power electromagnetic energy harvesting system for self-powering transmission line vibration deicing robot. Mech. Syst. Signal. Process. 2021, 151, 107369. [CrossRef]

115. Cao, X.; Chiang, W.-J.; King, Y.-C.; Lee, Y.-K. Electromagnetic Energy Harvesting Circuit with Feedforward and Feedback DC-DC PWM Boost Converter for Vibration Power Generator System. IEEE Trans. Power Electron. 2007, 22, 679-685. [CrossRef]

116. Proynov, P.P.; Szarka, G.D.; Stark, B.H.; McNeill, N. Resistive matching with a feed-forward controlled non-synchronous boost rectifier for electromagnetic energy harvesting. In Proceedings of the 2013 Twenty-Eighth Annual IEEE Applied Power Electronics Conference and Exposition (APEC), Long Beach, CA, USA, 17-21 March 2013; pp. 3081-3086.

117. Huang, T.-C.; Leu, Y.-G.; Huang, C.-W. Powering IoTs with a feedforward quasi universal boost converter energy harvester. Energy 2017, 133, 879-886. [CrossRef]

118. Wang, X.; Liang, X.; Wei, H. A study of electromagnetic vibration energy harvesters with different interface circuits. Mech. Syst. Signal. Process. 2015, 58-59, 376-398. [CrossRef]

119. Dong, X.; Huang, X. A Non-Resonant Type Electromagnetic Energy Harvester for Scavenging Vibration Energy. In Proceedings of the 2018 IEEE Sensors Applications Symposium (SAS), New Delhi, India, 28-31 October 2018; pp. 1-3.

120. Arroyo, E.; Badel, A. Electromagnetic vibration energy harvesting device optimization by synchronous energy extraction. Sens. Actuators A Phys. 2011, 171, 266-273. [CrossRef]

121. Xie, L.; Li, J.; Cai, S.; Li, X. Electromagnetic Energy-Harvesting Damper With Multiple Independently Controlled Transducers: On-Demand Damping and Optimal Energy Regeneration. IEEE/ASME Trans. Mechatron. 2017, 22, 2705-2713. [CrossRef]

122. Thomas, S.; Reynolds, M.; Teizer, J. Electromagnetic Energy Harvesting for Sensing, Communication, and Actuation. In Proceedings of the 27th International Symposium on Automation and Robotics in Construction, Bratislava, Slovakia, 25-27 June 2010; pp.183-192.

123. Cai, Q.-L.; Zhu, S. Enhancing the performance of electromagnetic damper cum energy harvester using microcontroller: Concept and experiment validation. Mech. Syst. Signal. Process. 2019, 134, 106339. [CrossRef]

124. Shen, W.; Zhu, S.; Zhu, H. Experimental study on using electromagnetic devices on bridge stay cables for simultaneous energy harvesting and vibration damping. Smart Mater. Struct. 2016, 25, 065011. [CrossRef]

125. Peigney, M.; Siegert, D. Low-Frequency Electromagnetic Energy Harvesting from Highway Bridge Vibrations. J. Bridg. Eng. 2020, 25, 04020056. [CrossRef]

126. Wang, X.; Liang, X.; Hao, Z.; Du, H.; Zhang, N.; Qian, M. Comparison of electromagnetic and piezoelectric vibration energy harvesters with different interface circuits. Mech. Syst. Signal. Process. 2016, 72-73, 906-924. [CrossRef]

127. Hasheminejad, S.M.; Rabiee, A.H.; Markazi, A.H.D. Dual-Functional Electromagnetic Energy Harvesting and Vortex-Induced Vibration Control of an Elastically Mounted Circular Cylinder. J. Eng. Mech. 2018, 144, 04017184. [CrossRef]

128. Zuo, L.; Cui, W. Dual-Functional Energy-Harvesting and Vibration Control: Electromagnetic Resonant Shunt Series Tuned Mass Dampers. J. Vib. Acoust. 2013, 135, 051018-0510189. [CrossRef] [PubMed]

129. Rahimi, A.; Zorlu, Ö.; Muhtaroğlu, A.; Külah, H. An electromagnetic energy harvesting system for low frequency applications with a passive interface ASIC in standard CMOS. Sens. Actuators A Phys. 2012, 188, 158-166. [CrossRef]

130. Tang, Y.; Khaligh, A. A Multiinput Bridgeless Resonant AC-DC Converter for Electromagnetic Energy Harvesting. IEEE Trans. Power Electron. 2015, 31, 2254-2263. [CrossRef]

131. P, V.K.; Mahesh, P.G.S. An Efficient Direct AC-DC Converter for Low Voltage Energy Harvesting System. Int. J. Sci. Dev. Res. 2017, 2, 426-432. 
132. Mitcheson, P.D.; Green, T.C.; Yeatman, E.M. Power processing circuits for electromagnetic, electrostatic and piezoelectric inertial energy scavengers. Microsyst. Technol. 2007, 13, 1629-1635. [CrossRef]

133. Wang, H.; Tang, Y.; Khaligh, A. A Bridgeless Boost Rectifier for Low-Voltage Energy Harvesting Applications. IEEE Trans. Power Electron. 2013, 28, 5206-5214. [CrossRef]

134. Siwakoti, Y.P.; Forouzesh, M.; Ha, P.N. Power Electronics Converters-An Overview, In Control of Power Electronic Converters and Systems; Chapter 1; Elsevier: Amsterdam, The Netherlands, 2018.

135. Bradai, S.; Naifar, S.; Trigona, C.; Baglio, S.; Kanoun, O. An electromagnetic/magnetoelectric transducer based on nonlinear RMSHI circuit for power harvesting and sensing. Measurement 2021, 177, 109307. [CrossRef]

136. Srinivasan, R.; Mangalanathan, U.; Gandhi, U. Dual input buck-boost converter for hybrid piezoelectric energy harvesterSupercapacitor sources. AEU Int. J. Electron. Commun. 2019, 111, 152926. [CrossRef]

137. Kraśny, M.J.; Bowen, C.R. A system for characterisation of piezoelectric materials and associated electronics for vibration powered energy harvesting devices. Measurement 2021, 168, 108285. [CrossRef]

138. Wang, H.; He, C.; Lv, S.; Sun, H. A new electromagnetic vibrational energy harvesting device for swaying cables. Appl. Energy 2018, 228, 2448-2461. [CrossRef]

139. Zhang, H.; Corr, L.R.; Ma, T. Effects of electrical loads containing non-resistive components on electromagnetic vibration energy harvester performance. Mech. Syst. Signal. Process. 2018, 101, 55-66. [CrossRef]

140. Cooley, C.G. Vibration properties of and power harvested by a system of electromagnetic vibration energy harvesters that have electrical dynamics. Mech. Syst. Signal. Process. 2017, 94, 237-252. [CrossRef]

141. Carneiro, P.; dos Santos, M.P.S.; Rodrigues, A.; Ferreira, J.A.; Simões, J.A.; Marques, A.T.; Kholkin, A.L. Electromagnetic energy harvesting using magnetic levitation architectures: A review. Appl. Energy 2020, 260, 114191. [CrossRef]

142. Baraskar, B.G.; Darvade, T.C.; Kambale, R.C.; Ryu, J.; Annapureddy, V. Harvesting stray magnetic field for powering wireless sensors. In Ferroelectric Materials for Energy Harvesting and Storage; Elsevier: Amsterdam, The Netherlands, 2021; pp. $249-278$.

143. Khandaker, M.R.A.; Wong, K.-K. Robust Secrecy Beamforming with Energy-Harvesting Eavesdroppers. IEEE Wirel. Commun. Lett. 2015, 4, 10-13. [CrossRef]

144. Pietsch, K.; Hiller, B.; Godenau, H. Optimization of an electromagnetic micro generator. In Proceedings of the 2014 IEEE Fourth International Conference on Consumer Electronics Berlin (ICCE-Berlin), Berlin, Germany, 7-10 September 2014; pp. 420-423.

145. Zhu, Y.; Moheimani, S.O.R.; Yuce, M.R. A 2-DOF wideband electrostatic transducer for energy harvesting and implantable applications. In Proceedings of the 2009 IEEE Sensors, Christchurch, New Zealand, 25-28 October 2009; Institute of Electrical and Electronics Engineers (IEEE): Piscataway, NJ, USA; pp. 1542-1545.

146. Gupta, R.K.; Shi, Q.; Dhakar, L.; Wang, T.; Heng, C.H.; Lee, C. Broadband Energy Harvester Using Non-linear Polymer Spring and Electromagnetic/Triboelectric Hybrid Mechanism. Sci. Rep. 2017, 7, 41396. [CrossRef]

147. Kausar, A.Z.; Reza, A.W.; Saleh, M.U.; Ramiah, H. Energizing wireless sensor networks by energy harvesting systems: Scopes, challenges and approaches. Renew. Sustain. Energy Rev. 2014, 38, 973-989. [CrossRef]

148. Beeby, S.P.; Zhu, D. Vibration energy harvesting: Fabrication, miniaturisation and applications. In Proceedings of the Smart Sensors, Actuators, and MEMS VII; and Cyber Physical Systems, Barcelona, Spain, 21 May 2015; p. 951703.

149. Edwards, B.; Aw, K.C.; Hu, A.P.; Tang, L.; Bryn, E. Hybrid electromagnetic-piezoelectric transduction for a frequency up-converted energy harvester. In Proceedings of the 2015 IEEE International Conference on Advanced Intelligent Mechatronics (AIM), Busan, Korea, 7-11 July 2015; pp. 1149-1154.

150. Pan, C.T.; Wu, T.T. Development of a rotary electromagnetic microgenerator. J. Micromech. Microeng. 2006, 17, 120-128. [CrossRef]

151. Glynne-Jones, P.; Tudor, M.; Beeby, S.; White, N. An electromagnetic, vibration-powered generator for intelligent sensor systems. Sens. Actuators A Phys. 2004, 110, 344-349. [CrossRef]

152. Cepnik, C.; Lausecker, R.; Wallrabe, U. Review on Electrodynamic Energy Harvesters-A Classification Approach. Micromachines 2013, 4, 168-196. [CrossRef]

153. Liu, H.; Chen, T.; Sun, L.; Lee, C. An Electromagnetic MEMS Energy Harvester Array with Multiple Vibration Modes. Micromachines 2015, 6, 984-992. [CrossRef]

154. Saibal, R. Electromechanical-MEMS Vibrational Energy Harvesting. Integrated ICT Hardware E Systems; Tyndall National Institute: Dublin, Ireland, 2021.

155. Uluşan, H.; Gharehbaghi, K.; Zorlu, Ö.; Muhtarolu, A.; Külah, H. A fully integrated and battery-free interface for low-voltage electromagnetic energy harvesters. IEEE Trans. Power Electron. 2015, 30, 3712-3719. [CrossRef]

156. Lu, Z.; Wen, Q.; He, X.; Wen, Z. A Nonlinear Broadband Electromagnetic Vibration Energy Harvester Based on Double-Clamped Beam. Energies 2019, 12, 2710. [CrossRef]

157. Sokolov, A.; Mallick, D.; Roy, S.; Kennedy, M.P.; Blokhina, E. Modelling and Verification of Nonlinear Electromechanical Coupling in Micro-Scale Kinetic Electromagnetic Energy Harvesters. IEEE Trans. Circuits Syst. I Regul. Pap. 2019, 67, 565-577. [CrossRef]

158. Gao, L.; Lu, S.; Xie, W.; Chen, X.; Wu, L.; Wang, T.; Wang, A.; Yue, C.; Tong, D.; Lei, W.; et al. A self-powered and self-functional tracking system based on triboelectric-electromagnetic hybridized blue energy harvesting module. Nano Energy 2020, $72,104684$. [CrossRef]

159. Moreno-Ramírez, C.; Iniesta, C.; González, A.; Olazagoitia, J.L. Development and Characterization of a Low-Cost Sensors System for an Acoustic Test Bench. Sensors 2020, 20, 6663. [CrossRef] 
160. Moreno, C.; González, A.; Olazagoitia, J.L.; Vinolas, J. The Acquisition Rate and Soundness of a Low-Cost Data Acquisition System (LC-DAQ) for High Frequency Applications. Sensors 2020, 20, 524. [CrossRef] [PubMed]

161. Hajinajaf, N.; Mehrabadi, A.; Tavakoli, O. Practical strategies to improve harvestable biomass energy yield in microalgal culture: A review. Biomass Bioenergy 2021, 145, 105941. [CrossRef]

162. Zhou, G.; Huang, L.; Li, W.; Zhu, Z. Harvesting Ambient Environmental Energy for Wireless Sensor Networks: A Survey. J. Sens. 2014, 2014, 1-20. [CrossRef]

163. Merz, C.; Kupris, G.; Niedernhuber, M. Design and optimization of a radio frequency energy harvesting system for energizing low power devices. In Proceedings of the 2014 International Conference on Applied Electronics, Pilsen, Czech Republic, 9-10 September 2014; Institute of Electrical and Electronics Engineers (IEEE): Piscataway, NJ, USA; pp. $209-212$.

164. Yunus, U. Design and Implementation of RF Energy Harvesting System for Low-Power Electronic Devices. J. Electron. Mater. 2016, 45, 3842-3847.

165. Thein, C.K.; Foong, F.M.; Shu, Y.-C. Damping ratio and power output prediction of an electromagnetic energy harvester designed through finite element analysis. Sens. Actuators A Phys. 2019, 286, 220-231. [CrossRef]

166. Iqbal, M.; Nauman, M.M.; Khan, F.U.; Abas, P.E.; Cheok, Q.; Iqbal, A.; Aissa, B. Multimodal Hybrid Piezoelectric-Electromagnetic Insole Energy Harvester Using PVDF Generators. Electronics 2020, 9, 635. [CrossRef]

167. Xi, F.; Pang, Y.; Liu, G.; Wang, S.; Li, W.; Zhang, C.; Wang, Z.L. Self-powered intelligent buoy system by water wave energy for sustainable and autonomous wireless sensing and data transmission. Nano Energy 2019, 61, 1-9. [CrossRef]

168. Prakasam, P.; Kumar, T.S.; Velmurugan, T.; Nandakumar, S. Efficient power distribution model for IoT nodes driven by energy harvested from low power ambient RF signal. Microelectron. J. 2020, 95, 104665. [CrossRef] 